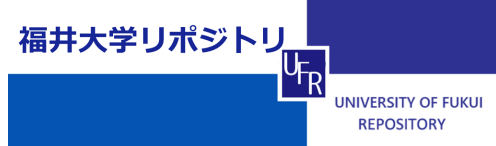

A syst emat i c i nvest i gat i on of T-stresses for a vari ety of cent er-cracked tensi on speci mens

\begin{tabular}{|l|l|}
\hline 著者 & Lu Kai , Meshi i Toshi yuki \\
\hline $\begin{array}{l}\text { j our nal or } \\
\text { publ i cat i on t i t l e }\end{array}$ & Theor et i cal and Appl i ed Fract ure Mechani cs \\
\hline vol une & 77 \\
\hline page r ange & $74-81$ \\
\hline year & $2015-06$ \\
\hline URL & ht t p: //hdl . handl e. net $/ 10098 / 8794$ \\
\hline
\end{tabular}




\section{Accepted Manuscript}

A systematic investigation of $T$-stresses for a variety of center-cracked tension specimens

Kai Lu, Toshiyuki Meshii

PII:

S0167-8442(14)20106-6

DOI:

http://dx.doi.org/10.1016/j.tafmec.2015.02.001

Reference:

TAFMEC 1566

To appear in:

Theoretical and Applied Fracture Mechanics

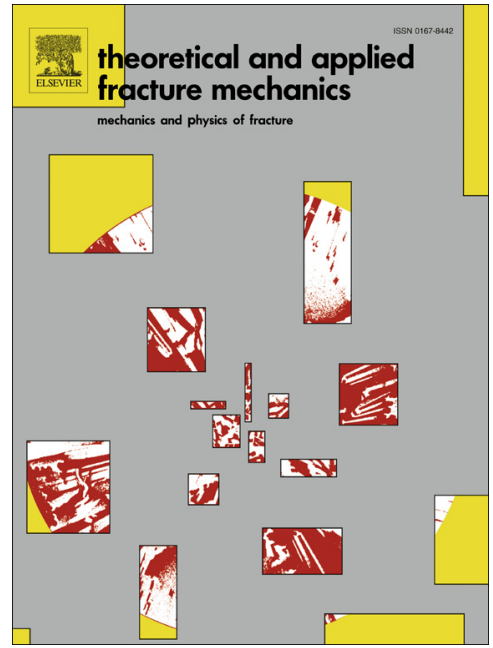

Please cite this article as: K. Lu, T. Meshii, A systematic investigation of $T$-stresses for a variety of center-cracked tension specimens, Theoretical and Applied Fracture Mechanics (2015), doi: http://dx.doi.org/10.1016/j.tafmec. 2015.02.001

This is a PDF file of an unedited manuscript that has been accepted for publication. As a service to our customers we are providing this early version of the manuscript. The manuscript will undergo copyediting, typesetting, and review of the resulting proof before it is published in its final form. Please note that during the production process errors may be discovered which could affect the content, and all legal disclaimers that apply to the journal pertain. 


\title{
A systematic investigation of $T$-stresses for a variety of center-cracked tension specimens
}

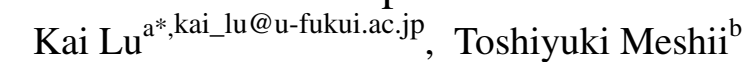

${ }^{a}$ Graduate School of Engineering, University of Fukui, 3-9-1 Bunkyo, Fukui, Fukui, Japan

${ }^{\mathrm{b}}$ Faculty of Engineering, University of Fukui, 3-9-1 Bunkyo, Fukui, Fukui, Japan

*Corresponding author. Fax: +81 776279764.

\begin{abstract}
In this work, a systematic investigation of three-dimensional (3D) $T$-stresses ( $T_{11}$ and $\left.T_{33}\right)$ was conducted using detailed elastic finite element analysis (FEA). The interaction integral method was applied to extract the $T$-stress solutions. Standard CCT specimens with a thickness-to-width ratio of $B /(2 W) \leq 0.0625$ and a crack length-to-thickness ratio of $2 a / B \geq 8$, as specified in ASTM E2472, were considered, and the cases of $B /(2 W)=0.1 \sim 1.0$ and $2 a / B=0.05 \sim 7$ were also added. From the FEA results, it was found that both $T_{11}$ and $T_{33}$ at the specimen mid-plane showed significant changes with crack lengths and specimen thicknesses for those CCT configurations that satisfy ASTM E2472. Because both the in-plane and out-of-plane $T$-stresses were negative and showed large variations for all the considered CCT specimens which was true even for the CCT specimens complying with the ASTM E2472 standard, it was noted that these CCT specimens that complying with the standard might show the test specimen size effect (including the crack length and specimen thickness effect) on the fracture toughness if tested.
\end{abstract}

\section{Keywords:}

$T$-stresses, Center-cracked specimen, Constraint effect, Finite element analysis, Fracture toughness 


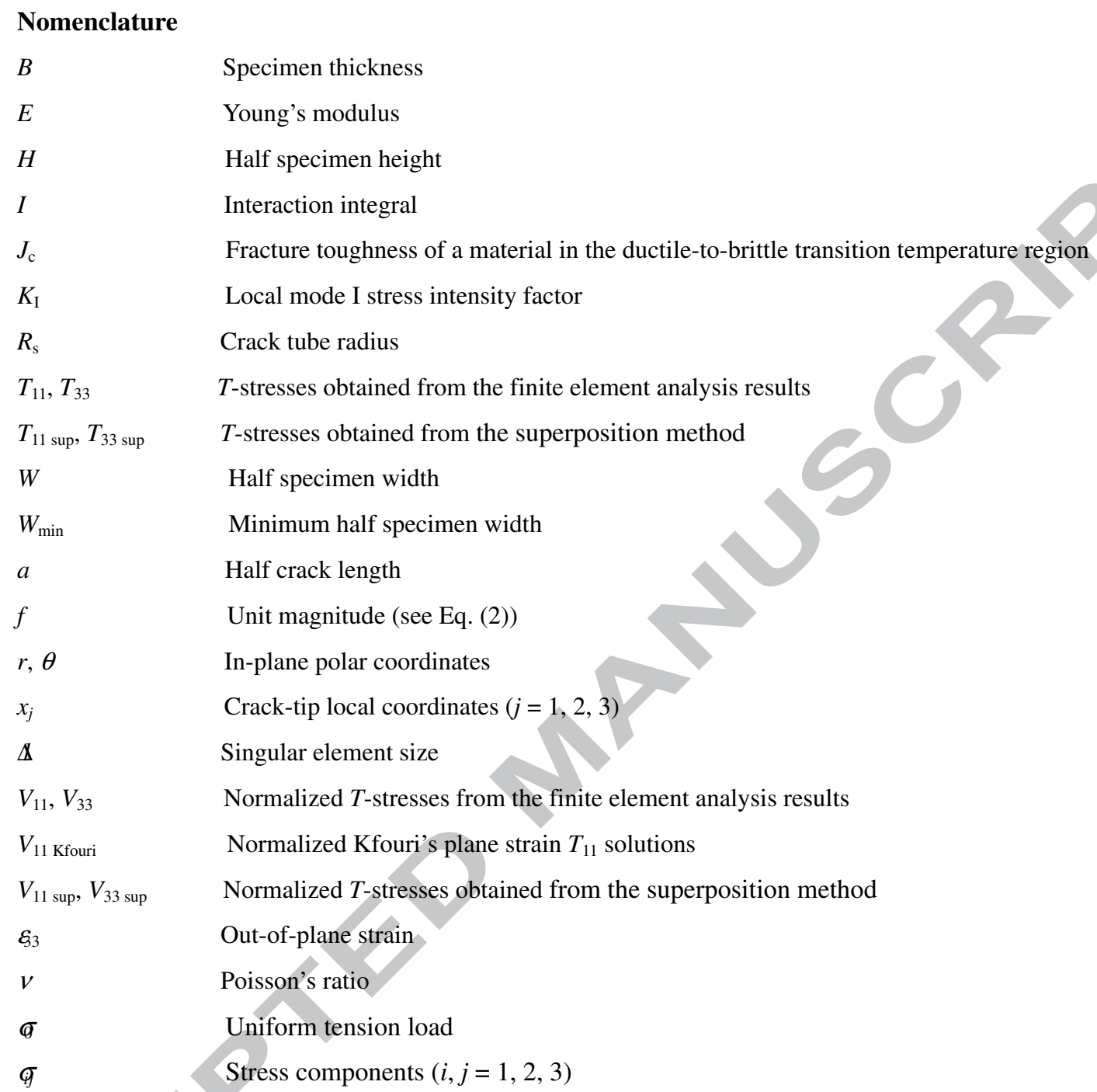

Specimen thickness

Young's modulus

Half specimen height

Interaction integral

Fracture toughness of a material in the ductile-to-brittle transition temperature region

Local mode I stress intensity factor

Crack tube radius

$T$-stresses obtained from the finite element analysis results

$T$-stresses obtained from the superposition method Half specimen width

Minimum half specimen width

Half crack length

Unit magnitude (see Eq. (2))

In-plane polar coordinates

Crack-tip local coordinates $(j=1,2,3)$

Singular element size

Normalized $T$-stresses from the finite element analysis results

Normalized Kfouri's plane strain $T_{11}$ solutions

Normalized $T$-stresses obtained from the superposition method

Out-of-plane strain

Poisson's ratio

Uniform tension load

Stress components $(i, j=1,2,3)$ 


\section{Introduction}

The crack-tip constraint difference caused by the specimen configuration and the size of fracture test specimens is known to show a strong effect on the measured fracture toughness [1, 2]. The past fracture toughness test results [3-5] indicated two common understandings, that is, (1) a high level of crack-tip constraint results in low fracture toughness, while a low constraint leads to a higher fracture toughness; (2) the change in the measured fracture toughness is small for a high constraint case but the fracture toughness is sensitive for a low constraint case. Therefore, the center-cracked tension (CCT) specimen in Fig. 1, which is considered to be a representative of the low constraint specimen $[6,7]$, should be sensitive to the constraint difference caused by specimen size difference $[3,8,9]$, if there is any. The past fracture toughness test results for the various sized CCT specimens [10] seemed to validate this sensitivity. Thus, studies on the crack-tip constraint difference for various sized CCT specimens were thought to be necessary. As a parameter to quantify the crack-tip constraint, the elastic $T$-stresses were considered [11].

The in-plane $T$-stress, $T_{11}$, which is thought to be a measure of the in-plane crack-tip constraint, has been extensively investigated in the previous works for various fracture toughness test specimens and cracked structures [7, 12-25].

In discussing the CCT specimens, six $T_{11}$ solutions in two-dimension (2D) [7, 13, 16, 19, 22, 24] and one in three-dimensions (3D) [24] are known. Five of them used the finite element method [7, $13,19,24]$, one of them used the boundary collocation method [16] and the other used the boundary element method [22]. In these six $2 \mathrm{D}$ works, five presented $T_{11}$ solutions for the plane strain condition [7, 13, 19, 22, 24] and one for the plane stress condition [16]. Among these five plane-stain $T_{11}$ solutions, Kfouri [13] and Tan and Wang's solutions [22] were obtained for isotropic materials with Poisson's ratio $v=0.3$. The difference in these two solutions was that Kfouri's solutions [13] covered the crack length-to-width ratio $a / W=0.1-0.6$, while Tan and Wang [22] covered $a / W=$ 0.2-0.6. The third plane strain $T_{11}$ solutions by Paulino and Kim [7] were obtained for both homogeneous and functionally graded materials. In case of a homogeneous material, they assumed $v$ $=0.3$ and considered cases for $a / W=0.1-0.8$. The fourth plane strain $T_{11}$ solutions by Henry and Luxmoore [24] were obtained for $a / W=0.1-0.9$, assuming a homogeneous material of $v=0.33$. The remaining one plane strain $T_{11}$ solutions by Shlyannikov [19] added cases for inclined cracks (mixed-mode loading), assuming a homogeneous material of $v=0.3$. The $T_{11}$ solutions presented for a non-inclined crack were for the cases $a / W=0.1-0.9$. The only plane stress $T_{11}$ solutions by Fett [16] were obtained for a homogeneous material of $v=0.25$ and for $a / W=0-1.0$. In addition to the effect of $a / W$ on $T_{11}$, he also examined the effect of $H / W$ in the range of $0.35-1.25$. In addition to the above six 2D works, $T_{11}$ solutions of 2D CCT specimens were also provided in some benchmark analyses (e.g., Chen and Wang [23]). Although various 2D $T_{11}$ solutions are available for CCT specimens, to the best of our knowledge, the 3D $T_{11}$ solutions of the CCT specimens can only be 
found in Henry and Luxmoore's paper [24], assuming a homogeneous material of $v=0.33$ and for the specific case of a thickness-to-width ratio $B /(2 W)$ of 0.25 . The planar size effect of $a / W=0.1-0.9$ was investigated. In addition to the results for $v=0.33$, the effect of Poisson's ratio $(v=0 \sim 0.495)$ was also investigated for the case of $a / W=0.7$. Although they noted out the existence of the 3D effect by comparing the 2D plane-strain $T_{11}$ with the 3D solutions, the out-of-plane $T$-stress, $T_{33}[11$, $18,20,26-32]$, which is thought to be a measure of the out-of-plane crack-tip constraint, has not been studied for the CCT specimens. Thus, in this work, a systematic investigation of the 3D $T$-stresses $\left(T_{11}\right.$ and $\left.T_{33}\right)$ for a variety of CCT specimens was conducted by using 3D elastic finite element analysis (FEA).

For that purpose, the standard CCT specimens, as specified in ASTM E2472 [33], with a minimum half specimen width of $W_{\min } \geq 150 \mathrm{~mm}$, a specimen height-to-width ratio of $H / W \geq 1.5$, a thickness-to-width ratio of $B /(2 W) \leq 0.0625$ and a crack length-to-thickness ratio of $2 a / B \geq 8$ were investigated. In addition, the cases of $B /(2 W)=0.1 \sim 1.0$ and $2 a / B=0.05 \sim 7$ were added to the systematic investigation.

Based on the FEA results, it was found that the $3 \mathrm{D}$ in-plane $T_{11}$ at the specimen mid-plane was a monotonously decreasing function of the crack length when $a / W \geq 0.3$ and showed a slight change with the crack length when $a / W<0.3$. Another finding was that the mid-plane $T_{11}$ showed a variation as high as $22 \%$ in the range of $B /(2 W)=0.01$ to 0.0625 at $a / W=0.5$, even though these $B /(2 W)$ ratios satisfy ASTM E2472 [33]. The newly obtained mid-plane $T_{33}$ was negative for all of the cases considered. The mid-plane $T_{33}$ was a monotonously increasing function of the specimen thickness. In particular, $T_{33}$ showed a significant change for the cases of $B /(2 W) \leq 0.0625$ and $2 a / B \geq 8$, even for those configurations that satisfy ASTM E2472 [33]. Because both the in-plane and out-of-plane $T$-stresses were negative for the CCT specimens and showed large variations for all the considered CCT specimens which is true even for cases complying with the standard ASTM E2472 [33], it was noted that these CCT specimens that complying with the standard might show the test specimen size effect (including the crack length and specimen thickness effect) on the fracture toughness if tested.

Fig. 1. CCT specimen

\section{2. $T$-stress}

In an isotropic and linear elastic 3D body containing a crack subjected to symmetric (mode I) loading, the leading two terms in the Williams series expansion [34] of the crack-tip stress fields near the crack front can be written as follows [14]: 


$$
\left\{\begin{array}{l}
\sigma_{11} \\
\sigma_{22} \\
\sigma_{33} \\
\sigma_{12} \\
\sigma_{23} \\
\sigma_{31}
\end{array}\right\}=\frac{K_{1}}{\sqrt{2 \pi r}}\left\{\begin{array}{c}
\cos \frac{\theta}{2}\left(1-\sin \frac{\theta}{2} \sin \frac{3 \theta}{2}\right) \\
\cos \frac{\theta}{2}\left(1+\sin \frac{\theta}{2} \sin \frac{3 \theta}{2}\right) \\
2 v \cos \frac{\theta}{2} \\
\sin \frac{\theta}{2} \cos \frac{\theta}{2} \cos \frac{3 \theta}{2} \\
0 \\
0
\end{array}\right\}+\left\{\begin{array}{c}
T_{11} \\
0 \\
T_{33} \\
0 \\
0 \\
0
\end{array}\right\}
$$

where $r$ and $\theta$ are the in-plane polar coordinates of the plane normal to the crack front shown in Fig. $2[28,32], K_{\mathrm{I}}$ is the local mode I stress intensity factor (SIF) and vis Poisson's ratio. Here, $x_{1}$ is the direction formed by the intersection of the plane normal to the crack front and the crack plane. $T_{11}$ and $T_{33}$ are the amplitudes of the second-order terms in the three-dimensional series expansions of the crack front stress field in the $x_{1}$ and $x_{3}$ directions, respectively.

Fig. 2 Three-dimensional coordinate system for the region along the crack front [28, 32]

Several methods have been proposed to evaluate the elastic $T$-stresses for different cracked geometries in recent studies. Sherry et al. [15] gave a brief summary of the different methods used for calculating the in-plane $T$-stress $T_{11}$. Based on the works by Cardew et al. [12] and Kfouri [13], Nakamura and Parks [14] developed an interaction integral method to extract the elastic $T_{11}$ for 3D mode I crack problems with the related calculation of the crack-tip $T_{11}$ on the crack front as:

$T_{11}=\frac{E}{1-v^{2}}\left\{\frac{I}{f}+v \varepsilon_{33}\right\}$

where $E$ denotes Young's modulus, vis Poisson's ratio and $\varepsilon_{3}$ represents the out-of-plane strain at the crack-tip in the direction tangential to the crack front. $I$ represents the interaction integral, and $f$ indicates the unit magnitude $(f=1)$. In Eq. (2), it should be noted that, for a specified material, the in-plane $T_{11}$ will be affected by not only the interaction integral $I$ but also the out-of-plane strain $\varepsilon_{3}$.

For a 3D cracked problem, in addition to the in-plane $T_{11}$, Nakamura and Parks [14] were the first to define the relationship for determining the out-of-plane $T$-stress $T_{33}$ :

$T_{33}=E \varepsilon_{33}+v T_{11}$

According to Eq. (3), it is clear that the out-of-plane $T_{33}$ naturally depends on the out-of-plane strain $\varepsilon_{3}$ and inevitably shows its dependence on the in-plane $T_{11}$.

More details of the interaction integral method can be found in Nakamura and Parks [14].

\section{Finite Element Analysis}

3.1 Details of the elastic FEA

Our interest was focused on the influence of 3D effects on various CCT specimens. Thus, the 3D 
elastic FEA was run to calculate the elastic $T$-stresses $\left(T_{11}\right.$ and $\left.T_{33}\right)$ for different CCT specimens. The FEA model was configured with a through-thickness straight crack, as shown in Fig. 3(a). For all of the cases in the present FEA, the specimen width and specimen height was fixed as $2 W=300 \mathrm{~mm}$ and $2 H=600 \mathrm{~mm}$, respectively. The set $W$ and $H$ satisfy the size requirements specified in ASTM E2472 [33] of $W_{\min } \geq 150 \mathrm{~mm}$, and $H / W \geq 1.5$. $H=2 W$ was selected because the numerical results were reported as being slightly affected by the specimen height $[13,35,36]$ and because this value has been used as a guideline for many years [37].

To study the 3D $T$-stresses $\left(T_{11}\right.$ and $\left.T_{33}\right)$ for a variety of CCT specimens, the ASTM E2472 [33] standard CCT specimens with a thickness-to-width ratio $B /(2 W) \leq 0.0625$ and a crack length-to-thickness ratio $2 a / B \geq 8$ were investigated. In addition, the cases of $B /(2 W)=0.1 \sim 1.0$ and $2 a / B=0.05 \sim 7$ were added to the systematic investigation.

Considering the symmetry conditions of the CCT specimens (Fig. 3(a)), the 1/8 symmetric model was built using the software FEA Crack [38], as shown in Fig. 3(b). The finite element model was generated using twenty-node isoparametric 3D solid elements with reduced $(2 \times 2 \times 2)$ Gauss integration. Sixteen singular elements were always used around the crack-tip throughout the calculations. A constant crack tube radius, $R_{\mathrm{s}}=1.0 \mathrm{~mm}$, was set with twenty equivalent rings spaced inside it (Fig. 3(c)). The smallest element size $\Delta$ relative to the crack length in the created models was in the range of $(0.42 \sim 6.7) \times 10^{3}$, as summarized in Table A.1. For the present FEA models, 78,720 to 93,632 elements with a total of 332,459 to 393,141 nodes were generated. The detailed mesh generation information is summarized in the Appendix.

The material is assumed to be isotropic and linearly elastic. The Young's modulus $E=206 \mathrm{GPa}$ and Poisson's ratio $v=0.3$ were adopted in the present FEA.

Because of the symmetry conditions (Fig. 3(a)), the displacements normal to the symmetry planes of the 1/8 symmetric FEA model were fixed, and they are grey-colored in Fig. 3(b). In applying a remote tensile loading, a uniform stress $\sigma=1 \mathrm{MPa}$ was applied on the remote plane $x_{2}=$ $H$ at the far-end of the model.

WARP3D [39] was used as the FEA solver.

Fig. 3 Typical 1/8 symmetric finite element model of a CCT specimen

$(2 W=300 \mathrm{~mm}, H / W=2, B /(2 W)=0.5$ and $a / W=0.5)$. Note that the detailed information for the mesh generation parameters ( $\mathbb{X}, \mathrm{CD}, \mathrm{NR}$ and na) is summarized in the Appendix.

\subsection{Validation of the evaluated $T$-stresses}

For all current FEAs, the $T$-stress results were evaluated by taking the average values obtained from domain 2 to domain 20 (domain $m$ consists of the elements from the $1^{\text {st }}$ ring to the $m^{\text {th }}$ ring). $T$ values were found to be independent on the chosen domains, as the differences in the $T$-stress results 
from domain 2 to domain 20 were within $0.1 \%$ of each other. We focused our attention on the specimen mid-plane $T$-stresses under the assumption that fracture initiation occurs at this location (e.g., $[10,27,28])$, and reported the $T$-stress solutions in the normalized form of $V_{k k}=T_{k k} / \sigma(k=1$ or $3)$.

Before summarizing the various $T$-stress solutions for CCT specimens with large crack length and thickness variations, the FEA model and evaluated $T$-stresses are validated in two steps. First, our 3D $T_{11}$ solutions at the specimen mid-plane for the thickest specimen of $B /(2 W)=1.0$ were compared with Kfouri's $2 \mathrm{D}$ plane strain $T_{11}$ solutions [13]. This ratio, $B /(2 W)=1.0$, was selected to confirm whether the 3D $T_{11}$ solutions might approach the plane strain values for a large thickness even though $B /(2 W)=1.0(B=300 \mathrm{~mm})$ might not be realistic for a CCT specimen. Note that Kfouri's plane strain solutions [13] are only available for $a / W=0.1$ to 0.6 .

In Fig. 4 and Table 1, the present mid-plane $V_{11}$ solutions show a relatively large difference compared with Kfouri's solutions, $V_{11 \text { Kfouri }}[13]$ as $5.4 \%$ for $a / W=0.5$ and $9.5 \%$ for $a / W=0.6$. When comparing the present mid-plane $V_{11}$ solutions for $B /(2 W)=0.5$ and 1.0 as summarized later in Table 2, it is found that the present $V_{11}$ solutions have not shown the saturating tendency for $B /(2 W)$ $=1.0$. Moreover, for a thick specimen with $B /(2 W) \geq 0.5$, the difference between the present $V_{11}$ solutions and Kfouri's solutions [13] increases. This result indicates that the stress state for a CCT specimen with a large thickness may deviate from the plane strain condition, which seems to contradict the common understanding that a thick specimen approaches the plane strain condition. Thus, we proceeded to the second step for $T$-stress validations.

Fig. 4 Comparison of the normalized 3D mid-plane $T_{11}$ solutions $\left(V_{11}=T_{11} / \varnothing\right)$ with Kfouri's 2D plane strain solutions [13] and the solutions from the superposition method for the CCT specimens with $B /(2 W)=1.0(v=0.3)$

The second step was to apply the superposition method for $T_{11}$ [18] and $T_{33}$ [31] in this work for validation. For example, in the case of $B /(2 W)=1.0$, the normalized mid-plane $T$-stress solutions from the superposition method (designated as $V_{11 \text { sup }}$ and $V_{33 \text { sup }}$ ) were compared with the mid-plane $V_{11}$ and $V_{33}$ solutions from the present FEA, as summarized in Table 1. It is clear from Table 1 that the maximum difference of the mid-plane $V_{11}$ and $V_{11}$ sup solutions is $0.03 \%$ and the maximum difference for the mid-plane $V_{33}$ and $V_{33}$ sup solutions is $0.16 \%$.

Although only one validation example of $B /(2 W)=1.0$ is presented in this paper, the validations for the other CCT models have also been confirmed. Considering all cases, the maximum difference for the mid-plane $V_{11}$ and $V_{11 \text { sup }}$ solutions is $0.03 \%$ and the maximum difference for the mid-plane $V_{33}$ and $V_{33 \text { sup }}$ solutions is $0.40 \%$. Thus, it is concluded that the present FEA models were suitable and that the obtained $T$-stress solutions have sufficient accuracy. 
Table 1 Comparisons of the mid-plane normalized $T$-stress results for CCT specimens from the present FEA and the superposition method $(2 W=300 \mathrm{~mm}, H / W=2, B /(2 W)=1.0 ; v=0.3)$

\subsection{T-stress solutions for CCT specimens}

Next, the normalized mid-plane $V_{11}$ values for all of the cases in the present FEA are summarized as shown in Table 2 and Fig. 5. Note that the mid-plane $V_{11}$ is always negative for all cases.

In Fig. 5, regardless of $B /(2 W)$, the mid-plane $V_{11}$ is a monotonously decreasing function of the crack length for $a / W \geq 0.3$, but it changes slightly for $a / W<0.3$, which is similar to Kfouri's $2 \mathrm{D}$ plane strain solutions [13]. Considering the ASTM E2472 [33] standard CCT specimens with $B /(2 W)$ $\leq 0.0625$ and $2 a / B \geq 8$, it is observed that the mid-plane $V_{11}$ shows a relatively small dependence on the crack length for $a / W \leq 0.5$, which satisfies the ASTM E2472 standard [33], and this result indicates that the $a / W$ specification in ASTM E2472 [33] is appropriate. Conversely, the mid-plane $V_{11}$ decreases significantly with the crack length for the CCT specimens with $a / W>0.5$. Similar results were also obtained by Henry and Luxmoore [24] and Shlyannikov [19] for the CCT specimens. The sudden decrease in $V_{11}$ for $a / W>0.5$ seems to mean that the in-plane crack-tip constraint will decrease for a CCT specimen with a deep crack, and this finding coincides with the past fracture toughness test results of the CCT specimens, which indicated that a higher $J_{\mathrm{c}}\left(J_{\mathrm{c}}\right.$ : fracture toughness of a material in the ductile-to-brittle transition temperature region) value is obtained for a CCT specimen with a deep crack than for a CCT specimen with a shallow crack [3, 40].

Although the $T_{11}$ stress is thought to be an in-plane constraint parameter, it is clear from Fig. 5 that the mid-plane $V_{11}$ also exhibits $3 \mathrm{D}$ effects, that is, the mid-plane $V_{11}$ decreases with an increase in $B /(2 W)$, regardless of $a / W$. A similar tendency was found by Nakamura and Parks for a single edge-cracked plate under tension [14] and during our recent experience with the $\operatorname{SE}(B)$ specimens [28]. As seen in Fig. 5, the mid-plane $T_{11}$ showed a variation as high as $22 \%$ in the range of $B /(2 W)=$ 0.01 to 0.0625 at $a / W=0.5$ even though this set of $B /(2 W)$ and $a / W$ satisfies ASTM E2472 [22].

Table 2 Normalized $T_{11}$ solutions $\left(V_{11}=T_{11} / \Phi\right)$ at the specimen mid-plane for CCT specimens ( $\left.V=0.3\right)$

Fig. 5 Normalized $T_{11}$ solutions $\left(V_{11}=T_{11} / \Phi\right)$ at the specimen mid-plane for CCT specimens $(v=0.3)$

Table 3 and Fig. 6 summarize the mid-plane $V_{33}$ solutions for various thicknesses and crack depths. The newly obtained mid-plane $T_{33}$ is negative for all of the cases considered. In Fig. 6, it is observed that $V_{33}$ is a monotonously increasing function of $B /(2 W)$, as expected. Specifically, $T_{33}$ shows a significant change for the cases of $B /(2 W) \leq 0.0625$ and $2 a / B \geq 8(a / W \leq 0.5)$ even though 
these configurations satisfy ASTM E2472 [33]. However, it is observed that the increase in $V_{33}$ with $B /(2 W)$ for $B /(2 W) \leq 0.0625$ is smaller than that for $B /(2 W) \geq 0.1$.

In summary, both the in-plane and out-of-plane $T$-stresses were negative and showed large variations for all the considered CCT specimens. This was true even for cases complying with the ASTM E2472 [33].

Table 3 Normalized $T_{33}$ solutions $\left(V_{33}=T_{33} / \varnothing\right)$ at the specimen mid-plane for CCT specimens $(v=0.3)$

Fig. 6 Normalized $T_{33}$ solutions $\left(V_{33}=T_{33} / \Phi\right)$ at the specimen mid-plane

for CCT specimens $(v=0.3)$

\section{Discussion}

Although the minimum thickness-to-width ratio $B /(2 W)=0.01$ might seem unrealistic, there is a fracture toughness test for a CCT specimen with $B /(2 W)=0.003$ reported in [10].

Because both the mid-plane $T$-stresses $\left(T_{11}\right.$ and $\left.T_{33}\right)$ were negative for the CCT specimens and showed large variations for all the considered CCT specimens, which was true even for cases complying with the ASTM E2472 [33], it was noted that these CCT specimens that complying with the standard might show the test specimen size effect (including the crack length and specimen thickness effect) on the fracture toughness if tested.

In addition to the mid-plane $T$-stress solutions, the variations of the normalized $V_{11}$ and $V_{33}$ solutions in the thickness direction along the crack front were studied for all cases. The similar tendency of the $V_{11}$ and $V_{33}$ distributions in the thickness direction for the CCT specimens with various thicknesses was obtained regardless of $a / W$. Here, an example case of $a / W=0.5$ with various thicknesses is summarized in the following figures. Note that the mid-side node values from the FEA results were excluded. In these figures, $x_{3}=0$ represents the value at the specimen mid-plane and $x_{3}$ $=B / 2$ corresponds to the value at the free surface.

As observed in Fig. 7, the normalized in-plane $T_{11}\left(V_{11}\right)$ distributions in the specimen thickness direction show an overall non-negligible variation for most of the cases studied in this work. There might be an opinion that $T_{11}$ in the thickness direction will show nearly no variation for a very thin specimen. However, considering the ASTM E2472 standard CCT specimens with $B /(2 W) \leq 0.0625$, it is clear from Fig. 7 that the variation of $V_{11}$ in the thickness direction increases visibly as $B /(2 W)$ decreases and that the largest variation of the $V_{11}$ distribution is observed as $16.5 \%$ for the thinnest specimen of $B /(2 W)=0.01$ in the range of $x_{3} /(B / 2)=0$ to 0.8 . When $B /(2 W)>0.0625$, it is observed that the overall variation of the $V_{11}$ distributions becomes small. However, for an extremely thick specimen of $B /(2 W)=1.0(B=300 \mathrm{~mm})$, which might be considered to be unrealistic, the variation of $V_{11}$ in the thickness direction is also non-negligible, with a $9.5 \%$ variation observed in the range of 
$x_{3} /(B / 2)=0$ to 0.8. A similar tendency can be found for a thick $\mathrm{SE}(\mathrm{B})$ test specimen (the thickness-to-width ratio is two), as reported in our recent work [28].

Fig. 7 Normalized $T_{11}$ solutions $\left(V_{11}=T_{11} / \varnothing\right)$ vs. $x_{3} /(B / 2)$ for the CCT specimens with various thicknesses $(a / W=0.5 ; v=0.3)$

Conversely, the normalized out-of-plane $T_{33}$ distributions in Fig. 8 decrease in the thickness direction, considering that the ordinate of this figure ranges from -14 to 0 . The decreasing tendency is more visible for the ASTM standard CCT specimens with $B /(2 W) \leq 0.0625$, especially for the case of $B /(2 W)=0.01$, because the difference in $V_{33}$ in the range of $x_{3} /(B / 2)=0$ to 0.8 is $76 \%$. However, the rate of decrease in $V_{33}$ becomes small as $B /(2 W)$ increases, which is clear for the case of $B /(2 W)$ $=1.0$ (the difference of $V_{33}$ in the range of $x_{3} /(B / 2)=0$ to 0.8 is $31 \%$ ). A similar result can be obtained for the $\mathrm{SE}(\mathrm{B})$ test specimen in our recent work [28].

Fig. 8 Normalized $T_{33}$ solutions $\left(V_{33}=T_{33} / \varnothing\right)$ vs. $x_{3} /(B / 2)$ for the CCT specimens with various thicknesses $(a / W=0.5 ; v=0.3)$

It should also be noted that both $T_{11}$ and $T_{33}$ diverge near the free surface $\left(x_{3} /(B / 2)=0.8\right.$ to 1.0$)$ because $\varepsilon_{3}$ tends to be singular in the region close to the free surface and cannot be accurately calculated using the present FEA method [14, 28, 41]. Thus, the $T$-stresses near the free surface calculated by the present FEA method require further study.

In addition to the $3 \mathrm{D}$ effects on CCT's $T$-stresses presented in this paper, another remaining interest is the Poisson's ratio effect on the $T$-stresses. Among the seven prior works on CCT $T$-stresses, Henry and Luxmoore [24] were the only researchers who examined the effects of Poisson's ratio vby obtaining the 3D mid-plane $T_{11}$ solutions of CCT specimens for the case of $B /(2 W)=0.25$ and $a / W=0.7$. From their results for $v=0,0.1,0.2,0.33,0.4$ and 0.495 , they concluded that $T_{11} \propto v$ Let us see whether this is true and the same relationship is obtained for various thicknesses. Also of interest is the relationship between $T_{33}$ and $k$ which was not presented by them.

Fig. 9(a) is a comparison of the present mid-plane $V_{11}$ solutions of $B /(2 W)=0.25$ with Henry and Luxmoore's results obtained from both the boundary layer method (BLM) and the displacement field method (i.e., uniform displacement applied on the far end of the specimens) [24]. Although Henry and Luxmoore concluded that the relationship $T_{11} \propto v$ could be obtained from their results, it is clearly observed from Fig. 9(a) that their conclusion $\left(T_{11} \propto\right.$ v) seems to be a rough compilation and that, rigorously speaking, $V_{11}$ was a monotonously increasing function of $v$ The present results are close to their result according to BLM, which they noted to be more accurate. To conclude, $V_{11}$ was a monotonously increasing function of $k$ which showed approximately $20 \%$ change in the range of $v=0$ to 
0.495 .

Fig. 9(b) summarizes how the relationship in Fig. 9(a) changes due to specimen thickness. In concrete, the effects of $v(v=0.1,0.3$ and 0.495$)$ on the mid-plane $V_{11}$ solutions for CCT specimens with $B /(2 W)=$ $0.01,0.0625,0.25,0.5$ and 1.0, for a case of $a / W=0.7$, were investigated. It is seen from Fig. 9 (b) that, although the mid-plane normalized $T_{11}\left(V_{11}\right)$ solutions monotonously increase with $\zeta$ the effect of $v$ on $V_{11}$ is strengthened for thin specimens and becomes negligible for thick specimens. It is worth noting that the change in the mid-plane $V_{11}$ with $v$ is not negligible for the ASTM standard specimens with $B /(2 W) \leq$ 0.0625. In summary, $T_{11}$ solutions are more sensitive to Poisson's ratio for a thin CCT specimen than those for a thick CCT specimen.

Fig. 9 Effects of Poisson's ratio von the mid-plane $V_{11}$ for the case of $a / W=0.7$ : (a) comparison of present $V_{11}$ for $B /(2 W)=0.25$ with Henry and Luxmoore's results [24] (b) present $V_{11}$ for various thicknesses

In addition to $a / W=0.7$, Fig. 10 (a) summarizes the effects of $\nu$ n the mid-plane $V_{11}$ solutions for CCT specimens with $a / W=0.5$ (standard in ASTM E2472 [33]), but of various thicknesses. In Fig. 10(a), the effects of $v$ on the mid-plane $V_{11}$ of $a / W=0.5$ are similar with those obtained for $a / W=0.7$ as shown in Fig. 9(b). However, compared with the cases of $a / W=0.7$, the change in the mid-plane $V_{11}$ due to the increase in $v$ becomes smaller for $a / W=0.5$. For an example case of $B /(2 W)=0.01$, the maximum difference of $V_{11}$ between the cases for $V=0.1$ and 0.495 was $394 \%$ for $a / W=0.5$, while the difference was $441 \%$ for the case of $a / W=0.7$.

In addition, Fig. 10(b) plots the effects of $v$ on the mid-plane $V_{33}$ solutions for CCT specimens with a standard $a / W=0.5$, but of various thicknesses. It is clear that the mid-plane $V_{33}$ show a monotonously decreasing function of Poisson's ratio $k$ regardless of $B /(2 W)$. The observed relationship was approximately linear, and this effect was larger compared with the cases of $V_{11}$. The relationship is expected from Eq. (3), in case of negative and constant $V_{11}$. Because $T_{11}$ was a monotonously increasing function of $V_{11}$, this enhanced the effect of $v$ on $V_{33}$. The decrease in $V_{33}$ is significant for the ASTM standard specimens with $B /(2 W) \leq 0.0625$, and the maximum difference of $V_{33}$ for $v=0.1$ and 0.495 is very large $(531 \%)$ for $B /(2 W)=0.01$, while the change in $V_{33}$ becomes smaller as $B /(2 W)$ increases, and the minimum difference of $V_{33}$ for $v=0.1$ and 0.495 is as large as $476 \%$ for $B /(2 W)=1.0$.

In summary, $T_{11}$ and $T_{33}$ are more sensitive to Poisson's ratio for a thin CCT specimen than those for a thick CCT specimen. The effects of Poisson's ratio on $T_{11}$ and $T_{33}$ become small as $a / W$ decreases.

Fig. 10 Effects of Poisson's ratio von the mid-plane $V_{11}$ and $V_{33}$ for a case of $a / W=0.5$ : (a) $V_{11}$ vs. $k$ (b) $V_{33}$ vs. $k$ 


\section{Conclusions}

The present study conducted a systematic investigation of the 3D $T$-stresses $\left(T_{11}\right.$ and $\left.T_{33}\right)$ for a variety of CCT specimens by running 3D elastic FEA. The conclusions obtained from this work are summarized as follows:

(1) Both the mid-plane $T_{11}$ and $T_{33}$ were negative for the CCT specimens considered in this study.

(2) The 3D in-plane $T_{11}$ at the specimen mid-plane was a monotonously decreasing function of the crack length at $a / W \geq 0.3$ and showed a slight change with the crack length at $a / W<0.3$.

(3) The mid-plane $T_{11}$ showed a variation as high as $22 \%$ in the range of $B /(2 W)=0.01$ to 0.0625 at $a / W=0.5$, even though these $B /(2 W)$ ratios that satisfy ASTM E2472.

(4) The newly obtained mid-plane $T_{33}$ was a monotonously increasing function of the specimen thickness. In particular, $T_{33}$ showed a significant change for the cases of $B /(2 W) \leq 0.0625$ and $2 a / B \geq$ 8, even though these configurations satisfy ASTM E2472.

\section{Acknowledgements}

This work was supported in part by JSPS KAKENHI Grant Number 24561038. Their support is greatly appreciated. 


\section{Appendix}

The detailed information of the mesh generation parameters is given in Table A.1. Please refer to Fig. 3 for the definitions of the mesh generation parameters $\Delta, C D, N R$ and na.

Table A.1 Summary of the detailed mesh generation (NE: number of elements) 


\section{List of figures}

Fig. 1 CCT specimen

Fig. 2 Three-dimensional coordinate system for the region along the crack front $[28,32]$

Fig. 3. Typical $1 / 8$ symmetric finite element model of a CCT specimen $(2 W=300 \mathrm{~mm}, H / W=2, B /(2 W)$ $=0.5$ and $a / W=0.5)$. Note that the detailed information for the mesh generation parameters $(\mathbb{X}, \mathrm{CD}, \mathrm{NR}$ and na) is summarized in the Appendix.

Fig. 4 Comparison of the normalized 3D mid-plane $T_{11}$ solutions $\left(V_{11}=T_{11} / \varnothing\right)$ with Kfouri's 2D plane strain solutions [13] and the solutions from the superposition method for the CCT specimens with $B /(2 W)$ $=1.0(v=0.3)$

Fig. 5 Normalized $T_{11}$ solutions $\left(V_{11}=T_{11} / ब\right)$ at the specimen mid-plane for CCT specimens $(v=0.3)$

Fig. 6 Normalized $T_{33}$ solutions $\left(V_{33}=T_{33} / \varnothing\right)$ at the specimen mid-plane for CCT specimens $(v=0.3)$

Fig. 7 Normalized $T_{11}$ solutions $\left(V_{11}=T_{11} / \varnothing\right)$ vs. $x_{3} /(B / 2)$ for the CCT specimens with various thicknesses $(a / W=0.5 ; v=0.3)$

Fig. 8 Normalized $T_{33}$ solutions $\left(V_{33}=T_{33} / \varnothing\right)$ vs. $x_{3} /(B / 2)$ for the CCT specimens with various thicknesses $(a / W=0.5 ; v=0.3)$

Fig. 9 Effects of Poisson's ratio von the mid-plane $V_{11}$ for the case of $a / W=0.7$ : (a) comparison of present $V_{11}$ for $B /(2 W)=0.25$ with Henry and Luxmoore's results [24] (b) present $V_{11}$ for various thicknesses

Fig. 10 Effects of Poisson's ratio $\nu$ on the mid-plane $V_{11}$ and $V_{33}$ for a case of $a / W=0.5$ : (a) $V_{11}$ vs. $k$ (b) $V_{33}$ vs. $V$ 


\section{List of tables}

Table 1 Comparisons of the mid-plane normalized $T$-stress results for CCT specimens from the present FEA and the superposition method $(2 W=300 \mathrm{~mm}, H / W=2, B /(2 W)=1.0 ; v=0.3)$

Table 2 Normalized $T_{11}$ solutions $\left(V_{11}=T_{11} / \oint\right)$ at the specimen mid-plane for CCT specimens $(v=0.3)$

Table 3 Normalized $T_{33}$ solutions $\left(V_{33}=T_{33} / \varnothing\right)$ at the specimen mid-plane for CCT specimens $(v=0.3)$ Table A.1 Summary of the detailed mesh generation (NE: number of elements) 


\section{References}

[1] X. K. Zhu, J.A. Joyce, Review of fracture toughness (G, K, J, CTOD, CTOA) testing and standardization, Engineering Fracture Mechanics 85 (2012) 1-46.

[2] V.N. Shlyannikov, N.V. Boychenko, A.M. Tartygasheva, In-plane and out-of-plane crack-tip constraint effects under biaxial nonlinear deformation, Engineering Fracture Mechanics 78 (2011) 1771-1783.

[3] J.D.G. Sumpter, A.T. Forbes, Constraint based analysis of shallow cracks in mild steel, Proceedings of TWI/EWI/IS International Conference on Shallow Crack Fracture Mechanics Test and Applications, Cambridge, UK, 23-24 September, 1992.

[4] W.A. Sorem, R.H. Dodds, S.T. Rolfe, Effects of crack depth on elastic-plastic fracture toughness, International Journal of Fracture 47 (1991) 105-126.

[5] M.T. Kirk, R.H. Dodds, The influence of weld strength mismatch on crack-tip constraint in single edge notch bend specimens, International Journal of Fracture 63 (1993) 297-316.

[6] X. K. Zhu, Y. J. Chao, Fully plastic crack-tip fields for CCP and DECP specimens under tension in non-hardening materials, International Journal of Solids and Structures 37 (2000) 577-598.

[7] G.H. Paulino, J.H. Kim, A new approach to compute $T$-stress in functionally graded materials by means of the interaction integral method, Engineering Fracture Mechanics 71 (2004) 1907-1950.

[8] N.P. O'Dowd, C.F. Shih, R.H. Dodds, The role of geometry and crack growth on constraint and implications for ductile/brittle fracture, in: M. Kirk, A. Bakker (Eds.), STP1244, Constraint effects in fracture theory and applicatons, Second volume, Philadelphia, American Society for Testing and Materials 1995, pp.134-159.

[9] J.D.G. Sumpter, An experimental investigation of the $T$ stress approach, in: E.M. Hackett (Eds.), STP 1171, Constraint Effects in Fracture, American Society for Testing and Materials, 1993, pp. 495-502.

[10] J.N. Masters , W.P. Haese, R.W. Finger, Investigation of deep flaws in thin walled tanks, NASA CR-72606, The Boeing Company, Seattle, Wash., Dec, 1969.

[11] M. Gupta, R.C. Alderliesten, R. Benedictus, A review of T-stress and its effects in fracture mechanics, Engineering Fracture Mechanics (2014), in press, $<$ http://dx.doi.org/10.1016/j.engfracmech.2014.1010.1013>.

[12] G.E. Cardew, M.R. Goldthorpe, I.C. Howard, A.P. Kfouri, On the Elastic T-term, in: B.A. Bibly, K.J. Miller, J.R. Willis (Eds.), Fundamentals of Deformation and Fracture, Cambridge: Cambridge University Press, 1984, pp. 465-476.

[13] A.P. Kfouri, Some evaluations of the elastic T-term using Eshelby's method, International Journal of Fracture 30 (1986) 301-315.

[14] T. Nakamura, D.M. Parks, Determination of elastic $T$-stress along three-dimensional crack fronts using an interaction integral, International Journal of Solids and Structures 29 (1992) 1597-1611.

[15] A.H. Sherry, C.C. France, M.R. Goldthorpe, Compendium of t-stress solutions for two and three dimensional cracked geometries, Fatigue \& Fracture of Engineering Materials \& Structures 18 (1995) 
$141-155$

[16] T. Fett, T-stresses in rectangular plates and circular disks, Engineering Fracture Mechanics 60 (1998) 631-652.

[17] X. Wang, Elastic T-stress for cracks in test specimens subjected to non-uniform stress distributions, Engineering Fracture Mechanics 69 (2002) 1339-1352.

[18] X. Wang, R. Bell, Elastic $T$-stress solutions for semi-elliptical surface cracks in finite thickness plates subject to non-uniform stress distributions, Engineering Fracture Mechanics 71 (2004) 1477-1496.

[19] V.N. Shlyannikov, $T$-stress for crack paths in test specimens subject to mixed mode loading, Engineering Fracture Mechanics 108 (2013) 3-18.

[20] Y.G. Matvienko, V.N. Shlyannikov, N.V. Boychenko, In-plane and out-of-plane constraint parameters along a three-dimensional crack-front stress field under creep loading, Fatigue \& Fracture of Engineering Materials \& Structures 36 (2013) 14-24.

[21] V.N. Shlyannikov, N.V. Boychenko, A.V. Tumanov, A. Fernández-Canteli, The elastic and plastic constraint parameters for three-dimensional problems, Engineering Fracture Mechanics 127 (2014) 83-96. [22] C.L. Tan, X. Wang, The use of quarter-point crack-tip elements for $T$-stress determination in boundary element method analysis, Engineering Fracture Mechanics 70 (2003) 2247-2252.

[23] C.H. Chen, C.L. Wang, Stress intensity factors and $T$-stresses for offset double edge-cracked plates under mixed-mode loadings, International Journal of Fracture 152 (2008) 149-162.

[24] B.S. Henry, A.R. Luxmoore, Three-dimensional evaluation of the T-stress in centre cracked plates, International Journal of Fracture 70 (1994) 35-50.

[25] M. R. Ayatollahi, M.R.M. Aliha., Analysis of a new specimen for mixed mode fracture tests on brittle materials, Engineering Fracture Mechanics 76 (2009) 1563-1573.

[26] V.F. González-Albuixech, E. Giner, J. Fernández-Sáez, A. Fernández-Canteli, Influence of the $T_{33}$-stress on the 3-D stress state around corner cracks in an elastic plate, Engineering Fracture Mechanics 78 (2011) 412-427.

[27] T. Meshii, K. Lu, R. Takamura, A failure criterion to explain the test specimen thickness effect on fracture toughness in the transition temperature region, Engineering Fracture Mechanics 104 (2013) 184-197.

[28] K. Lu, T. Meshii, Three-dimensional $T$-stresses for three-point-bend specimens with large thickness variation, Engineering Fracture Mechanics 116 (2014) 197-203.

[29] K. Lu, T. Meshii, Application of $T_{33}$-Stress to Predict the Lower Bound Fracture Toughness for Increasing the Test Specimen Thickness in the Transition Temperature Region, Advances in Materials Science and Engineering (2014) <http://dx.doi.org/10.1155/2014/269137>.

[30] T. Meshii, K. Lu, Y. Fujiwara, Extended investigation of the test specimen thickness (TST) effect on the fracture toughness $\left(J_{\mathrm{c}}\right)$ of a material in the ductile-to-brittle transition temperature region as a difference in the crack tip constraint - What is the loss of constraint in the TST effects on $J_{\mathrm{c}}$ ?, 
Engineering Fracture Mechanics (2014), in press, $<$ http://dx.doi.org/10.1016/j.engfracmech.2014.1007.1025>.

[31] T. Meshii, T. Tanaka, K. Lu, T-Stress solutions for a semi-elliptical axial surface crack in a cylinder subjected to mode-I non-uniform stress distributions, Engineering Fracture Mechanics 77 (2010) 2467-2478.

[32] T. Meshii, T. Tanaka, Experimental $T_{33}$-stress formulation of test specimen thickness effect on fracture toughness in the transition temperature region, Engineering Fracture Mechanics 77 (2010) 867-877.

[33] ASTM, E2472-06 standard test method for determination of resistance to stable crack extension under low-constraint conditions, Annual book of ASTM standards, 2006.

[34] M.L. Williams, On the stress distribution at the base of a stationary crack, Journal of Applied Mechanics 24 (1957) 111-114.

[35] M. Isida, Effect of width and length on stress intensity factors of internally cracked plates under various boundary conditions, International Journal of Fracture Mechanics 7 (1971) 301-316.

[36] Z. Wu, On the through-thickness crack with a curve front in center-cracked tension specimens, Engineering Fracture Mechanics 73 (2006) 2600-2613.

[37] J.C. Newman Jr, M. Jordan Haines, Verification of stress-intensity factors for various middle-crack tension test specimens, Engineering Fracture Mechanics 72 (2005) 1113-1118.

[38] Quest Integrity Group, 3D finite element software for cracks: Version 3.2 user's manual, Boulder, CO80301, USA, 2013.

[39] B. Healy, A. Gullerud, K. Koppenhoefer, A. Roy, S. RoyChowdhury, J. Petti, M. Walters, B. Bichon, K. Cochran, A. Carlyle, J. Sobotka, M. Messner, R.H. Dodds, WARP3D Release 17.5.3 Manual, Civil Engineering, Report No UIUC-ENG-95-2012, University of Illinois at Urbana-Champaign, 2014.

[40] J. Heerens, U. Zerbst, K.H. Schwalbe, Strategy for characterizing fracture toughness in the ductile to brittle transition regime, Fatigue \& Fracture of Engineering Materials \& Structures 16 (1993) 1213-1230. [41] A. Fernández-Canteli, E. Giner, J. Fernández-Sáez, D. Fernández-Zúñiga, A unified analysis of the in-plane and out-of-plane constraints in 3-D linear elastic fracture toughness, Proceedings of the 19th European Conference on Fracture, Kazan, Russia, 2012, pp.1-8. 
Table 1 Comparisons of the mid-plane normalized $T$-stress results for CCT specimens from the present FEA and the superposition method $(2 W=300 \mathrm{~mm}, H / W=2, B /(2 W)=1.0 ; \nu=0.3)$

\begin{tabular}{|c|c|c|c|c|c|c|c|c|c|c|}
\hline$a / W$ & 0.05 & 0.1 & 0.15 & 0.2 & 0.3 & 0.4 & 0.5 & 0.6 & 0.7 & 0.8 \\
\hline$V_{11 \text { Kfouri }}$ & $(\rightarrow)$ & -0.995 & $(\rightarrow$ & -1.028 & -1.076 & -1.136 & -1.219 & -1.350 & $(\rightarrow$ & $(\rightarrow)$ \\
\hline$V_{11}$ & -1.003 & -1.010 & -1.022 & -1.039 & -1.090 & -1.166 & -1.285 & -1.479 & -1.827 & .566 \\
\hline $\begin{array}{c}\left|\left(V_{11}-V_{11 \text { Kfouri }}\right) / V_{11 \text { Kfouri }}\right| \\
\times 100 \%\end{array}$ & $(\rightarrow)$ & 1.5 & $(\rightarrow$ & 1.1 & 1.3 & 2.6 & 5.4 & 9.5 & & $\rightarrow$ \\
\hline$V_{11 \text { sup }}$ & -1.003 & -1.010 & -1.022 & -1.039 & -1.090 & -1.166 & -1.285 & -1.479 & -1.827 & -2.566 \\
\hline $\begin{array}{c}\left|\left(V_{11}-V_{11 \text { sup }}\right) / V_{11 \text { sup }}\right| \\
\times 100 \%\end{array}$ & 0.02 & 0 & 0.02 & 0.03 & 0.01 & 0.02 & 0.0 & 0.01 & 0 & 0 \\
\hline$V_{33}$ & -0.5989 & -0.5953 & -0.5899 & -0.5837 & -0.5762 & -0.5826 & -0.6183 & -0.6930 & -0.8407 & -1.124 \\
\hline$V_{33 \text { sup }}$ & -0.5988 & -0.5953 & -0.5899 & -0.5838 & -0.5758 & -0.5831 & -0.6175 & -0.6941 & -0.8401 & -1.124 \\
\hline $\begin{array}{c}\left|\left(V_{33}-V_{33 \text { sup }}\right) / V_{33 \text { sup }}\right| \\
\times 100 \%\end{array}$ & 0.01 & 0 & 0.01 & 0.03 & 0.07 & 0.09 & 0.13 & 0.16 & 0.07 & 0.02 \\
\hline
\end{tabular}

$*(\neg$ : no result exists for comparison 
Table 2 Normalized $T_{11}$ solutions $\left(V_{11}=T_{11} / \varnothing\right)$ at the specimen mid-plane for CCT specimens $(v=0.3)$

\begin{tabular}{|c|c|c|c|c|c|c|c|c|c|c|}
\hline$B /(2 W)$ & 0.05 & 0.1 & 0.15 & 0.2 & 0.3 & 0.4 & 0.5 & 0.6 & 0.7 & 0.8 \\
\hline 0.01 & -0.9142 & -0.8811 & -0.8600 & -0.8468 & -0.8402 & -0.8612 & -0.9207 & -1.046 & -1.306 & -1.906 \\
\hline 0.025 & -0.9487 & -0.9290 & -0.9190 & -0.9156 & -0.9268 & -0.9660 & -1.046 & -1.197 & -1.491 & -2.146 \\
\hline 0.0625 & -0.9920 & -0.9616 & -0.9567 & -0.9593 & -0.9819 & -1.032 & -1.125 & -1.291 & -1.606 & -2.288 \\
\hline 0.1 & -1.012 & -0.9842 & -0.9730 & -0.9756 & -1.002 & -1.056 & -1.153 & -1.324 & -1.643 & -2.328 \\
\hline 0.25 & -1.009 & -1.020 & -1.020 & -1.019 & -1.036 & -1.090 & -1.189 & -1.365 & -1.698 & -2.457 \\
\hline 0.5 & -1.004 & -1.014 & -1.028 & -1.042 & -1.075 & -1.131 & -1.234 & -1.425 & -1.791 & -2.564 \\
\hline 1.0 & -1.003 & -1.010 & -1.022 & -1.039 & -1.090 & -1.166 & -1.285 & -1.479 & -1.827 & -2.566 \\
\hline
\end{tabular}


Table 3 Normalized $T_{33}$ solutions $\left(V_{33}=T_{33} / \varnothing\right)$ at the specimen mid-plane for CCT specimens $(v=0.3)$

\begin{tabular}{c|c|c|c|c|c|c|c|c|c|c}
\hline$a / W$ & 0.05 & 0.1 & 0.15 & 0.2 & 0.3 & 0.4 & 0.5 & 0.6 & 0.7 & 0.8 \\
\hline 0.01 & -1.048 & -1.453 & -1.778 & -2.067 & -2.600 & -3.142 & -3.758 & -4.516 & -5.562 & -7.267 \\
\hline 0.025 & -0.7086 & -0.9522 & -1.152 & -1.331 & -1.666 & -2.008 & -2.394 & -2.872 & -3.537 & -4.599 \\
\hline 0.0625 & -0.5272 & -0.6529 & -0.7718 & -0.8811 & -1.086 & -1.301 & -1.543 & -1.848 & -2.270 & -2.952 \\
\hline 0.1 & -0.5169 & -0.5568 & -0.6422 & -0.7253 & -0.8836 & -1.050 & -1.242 & -1.483 & -1.816 & -2.346 \\
\hline 0.25 & -0.5721 & -0.5305 & -0.5203 & -0.5385 & -0.6198 & -0.7203 & -0.8388 & -0.9882 & -1.193 & -1.537 \\
\hline 0.5 & -0.5929 & -0.5744 & -0.5539 & -0.5392 & -0.5409 & -0.5803 & -0.6504 & -0.7571 & -0.9411 & -1.317 \\
\hline 1.0 & -0.5989 & -0.5953 & -0.5899 & -0.5837 & -0.5762 & -0.5826 & -0.6183 & -0.6930 & -0.8407 & -1.124 \\
\hline
\end{tabular}




\section{ACCEPTED MANUSCRIPT}

Table A.1 Summary of the detailed mesh generation (NE: number of elements)

\begin{tabular}{|c|c|c|c|c|c|c|c|c|c|c|c|}
\hline$B /(2 W)$ & $a / W$ & 0.05 & 0.1 & 0.15 & 0.2 & 0.3 & 0.4 & 0.5 & 0.6 & 0.7 & 0.8 \\
\hline \multirow{4}{*}{0.01} & $\Delta a \times 10^{3}$ & 6.7 & 3.3 & 2.2 & 1.7 & 1.1 & 0.83 & 0.67 & 0.56 & 0.48 & 0.42 \\
\hline & $\mathrm{NE}$ of $\mathrm{CD}$ & 3 & 5 & 7 & 8 & 15 & 20 & 24 & 28 & 32 & 38 \\
\hline & NE of NR & 41 & 41 & 39 & 36 & 31 & 29 & 26 & 21 & 16 & 10 \\
\hline & NE of na (bias) & \multicolumn{10}{|c|}{$90(2)$} \\
\hline \multirow{4}{*}{0.025} & $\Delta N a \times 10^{3}$ & 6.7 & 3.3 & 2.2 & 1.7 & 1.1 & 0.83 & 0.67 & 0.56 & 0.48 & 0.42 \\
\hline & $\mathrm{NE}$ of $\mathrm{CD}$ & 3 & 5 & 7 & 8 & 15 & 20 & 24 & 28 & 32 & 38 \\
\hline & NE of NR & 42 & 42 & 40 & 38 & 32 & 30 & 24 & 20 & 14 & 8 \\
\hline & NE of na (bias) & \multicolumn{10}{|c|}{$90(2)$} \\
\hline \multirow{4}{*}{0.0625} & $\mathbb{N} a \times 10^{3}$ & 6.7 & 3.3 & 2.2 & 1.7 & 1.1 & 0.83 & 0.67 & 0.56 & 0.48 & 0.42 \\
\hline & $\mathrm{NE}$ of $\mathrm{CD}$ & 3 & 5 & 7 & 8 & 15 & 20 & 24 & 28 & 32 & 38 \\
\hline & NE of NR & 43 & 43 & 41 & 39 & 33 & 31 & 25 & 21 & 16 & 10 \\
\hline & NE of na (bias) & \multicolumn{10}{|c|}{$90(2)$} \\
\hline \multirow{4}{*}{0.1} & $\Delta / a \times 10^{3}$ & 6.7 & 3.3 & 2.2 & 1.7 & 1.1 & 0.83 & 0.67 & 0.56 & 0.48 & 0.42 \\
\hline & $\mathrm{NE}$ of $\mathrm{CD}$ & 3 & 5 & 7 & 8 & 15 & 20 & 24 & 28 & 32 & 38 \\
\hline & NE of NR & 40 & 40 & 38 & 35 & 35 & 27 & 23 & 20 & 16 & 11 \\
\hline & NE of na (bias) & \multicolumn{10}{|c|}{$90(2)$} \\
\hline \multirow{4}{*}{0.25} & $\Delta N a \times 10^{3}$ & 6.7 & 3.3 & 2.2 & 1.7 & 1.1 & 0.83 & 0.67 & 0.56 & 0.48 & 0.42 \\
\hline & $\mathrm{NE}$ of $\mathrm{CD}$ & 4 & 5 & 7 & 8 & 15 & 20 & 24 & 28 & 32 & 38 \\
\hline & NE of NR & 51 & 49 & 47 & 34 & 36 & 28 & 22 & 21 & 16 & 10 \\
\hline & NE of na (bias) & \multicolumn{10}{|c|}{$135(2)$} \\
\hline \multirow{4}{*}{0.5} & $\quad N a \times 10^{3}$ & 6.7 & 3.3 & 2.2 & 1.7 & 1.1 & 0.83 & 0.67 & 0.56 & 0.48 & 0.42 \\
\hline & $\mathrm{NE}$ of $\mathrm{CD}$ & 4 & 5 & 7 & 8 & 15 & 20 & 24 & 28 & 32 & 38 \\
\hline & NE of NR & 54 & 49 & 46 & 44 & 36 & 25 & 24 & 20 & 16 & 10 \\
\hline & NE of na (bias) & \multicolumn{10}{|c|}{$135(2)$} \\
\hline \multirow{4}{*}{1.0} & $\Delta N a \times 10^{3}$ & 6.7 & 3.3 & 2.2 & 1.7 & 1.1 & 0.83 & 0.67 & 0.56 & 0.48 & 0.42 \\
\hline & $\mathrm{NE}$ of $\mathrm{CD}$ & 4 & 6 & 7 & 8 & 15 & 20 & 24 & 25 & 32 & 38 \\
\hline & NE of NR & 40 & 40 & 40 & 40 & 36 & 25 & 24 & 20 & 16 & 10 \\
\hline & NE of na (bias) & \multicolumn{10}{|c|}{$189(2)$} \\
\hline
\end{tabular}




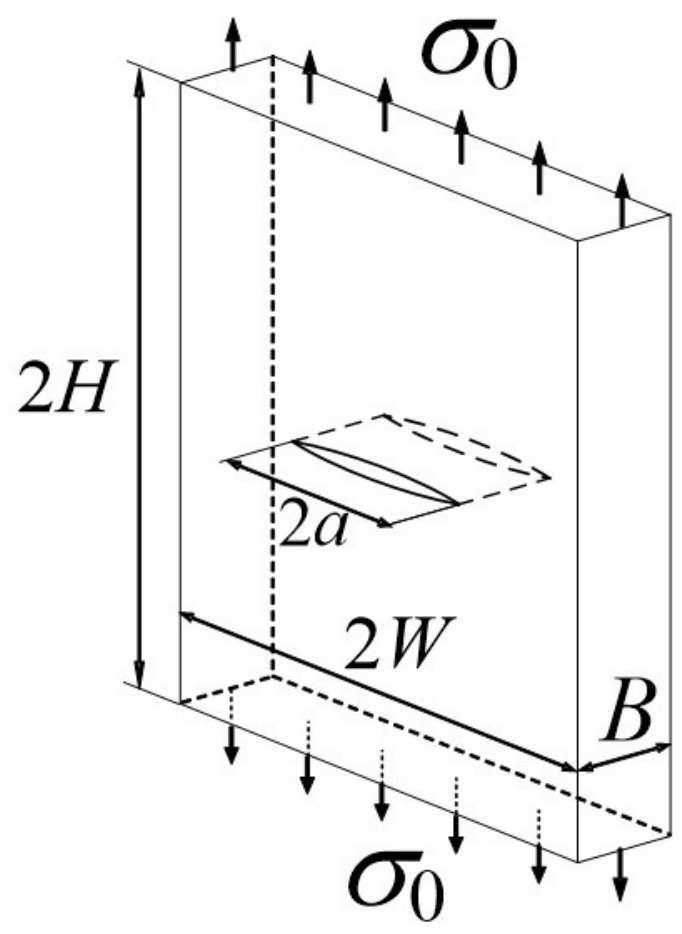

Fig. 1 CCT specimen 


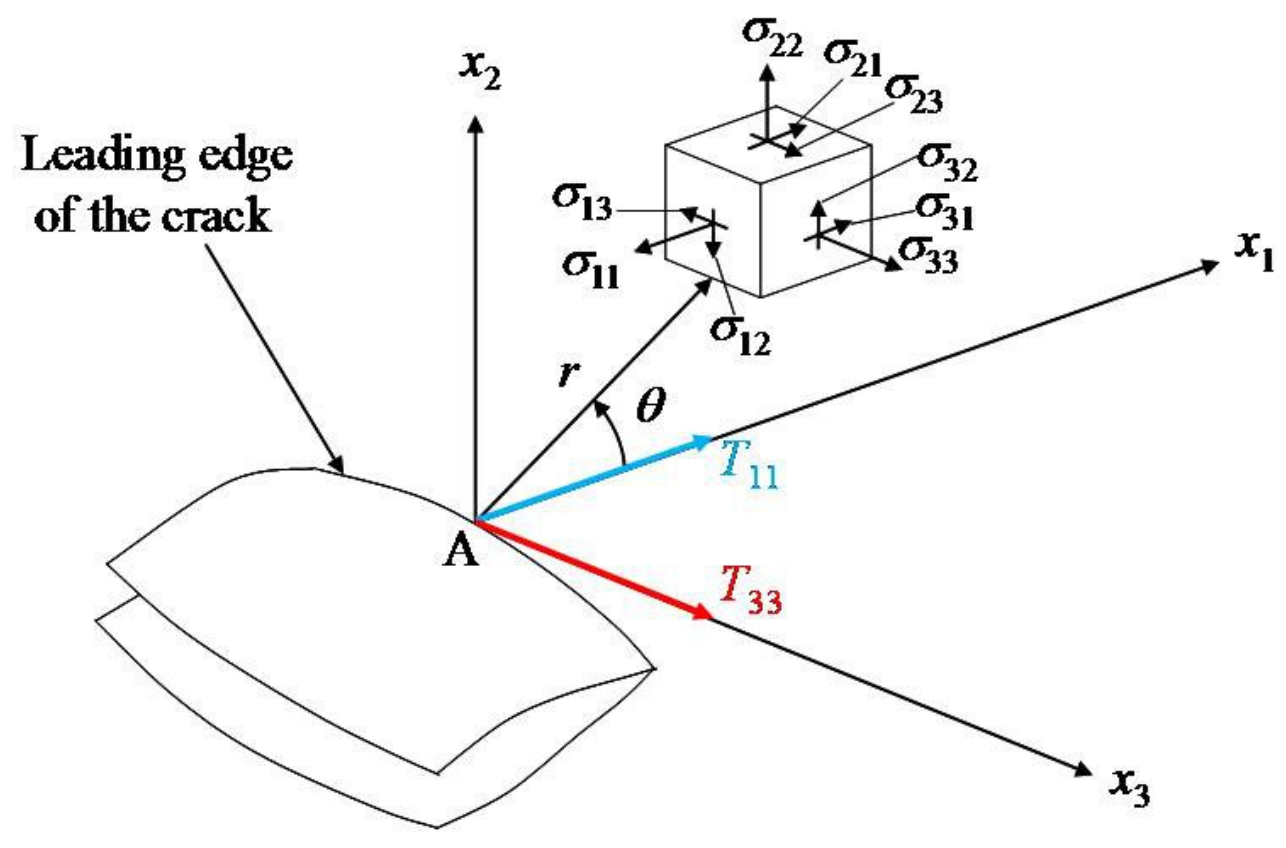

Fig. 2 Three-dimensional coordinate system for the region along the crack front [28, 32] 


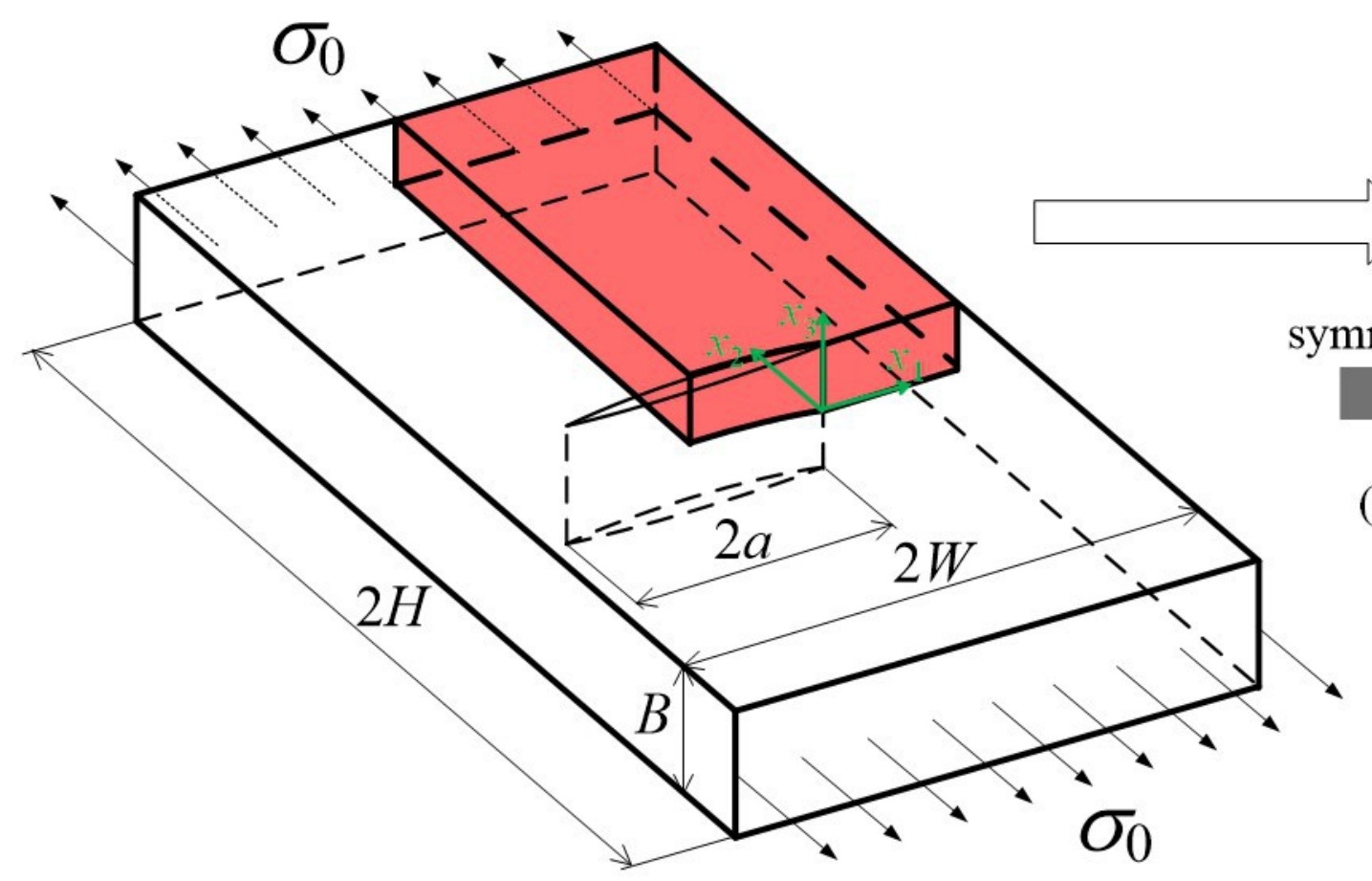

(a) Analyzed CCT model

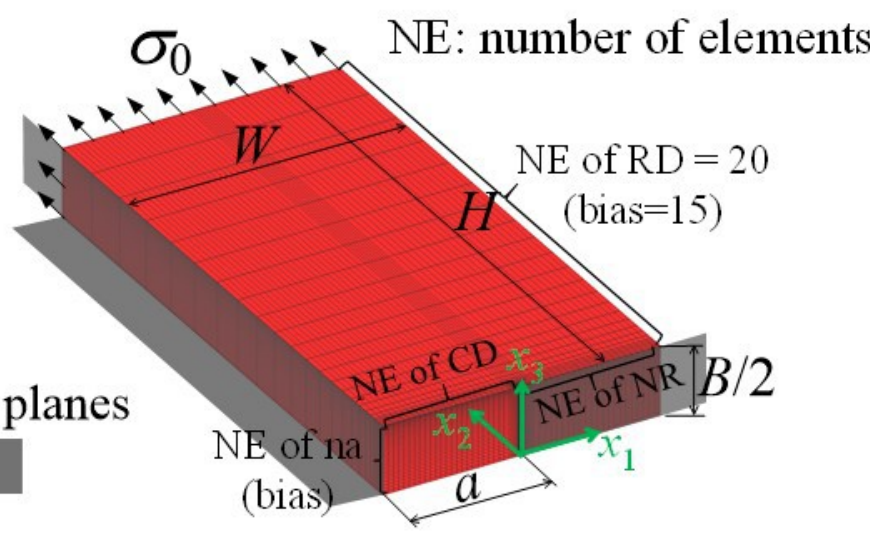

(b) Global mesh for the $1 / 8$ symmetric FEA model

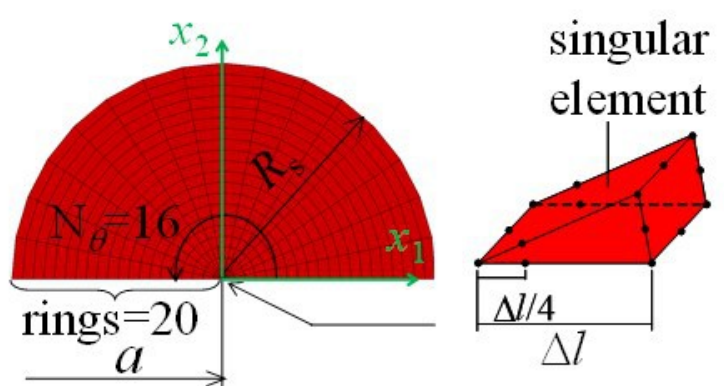

(c) Details of the crack-tip

Fig. 3. Typical 1/8 symmetric finite element model of a CCT specimen ( $2 W=300 \mathrm{~mm}, H / W=2, B /(2 W)=0.5$ and $a / W=0.5$ ). Note that the detailed information for the mesh generation parameters ( $\Delta l, \mathrm{CD}, \mathrm{NR}$ and na) is summarized in the Appendix. 


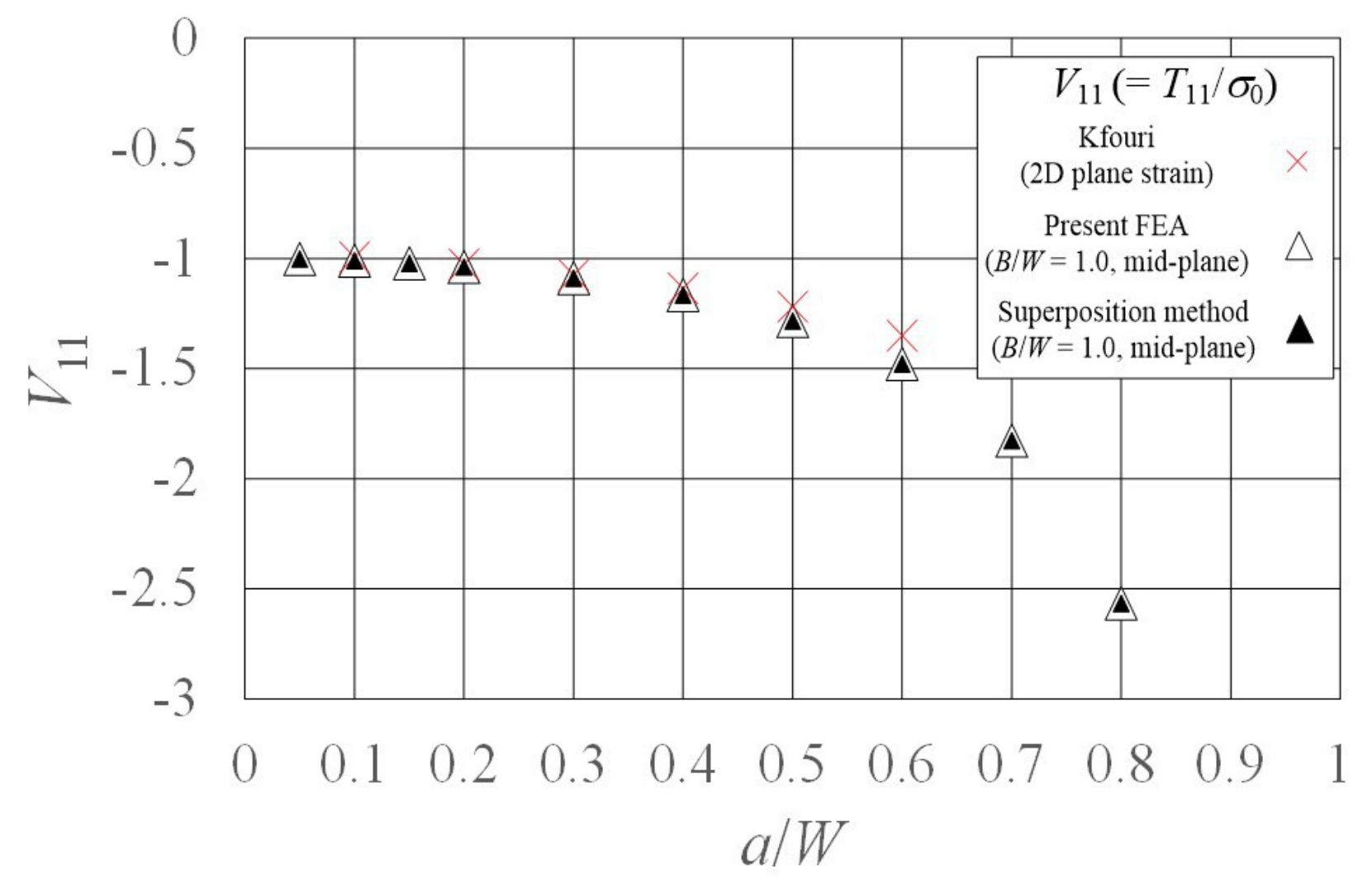

Fig. 4 Comparison of the normalized 3D mid-plane $T_{11}$ solutions $\left(V_{11}=T_{11} / \sigma_{0}\right)$ with Kfouri's 2D plane strain solutions [13] and the solutions from the superposition method for the CCT specimens with $B /(2 W)=1.0(v=0.3)$ 


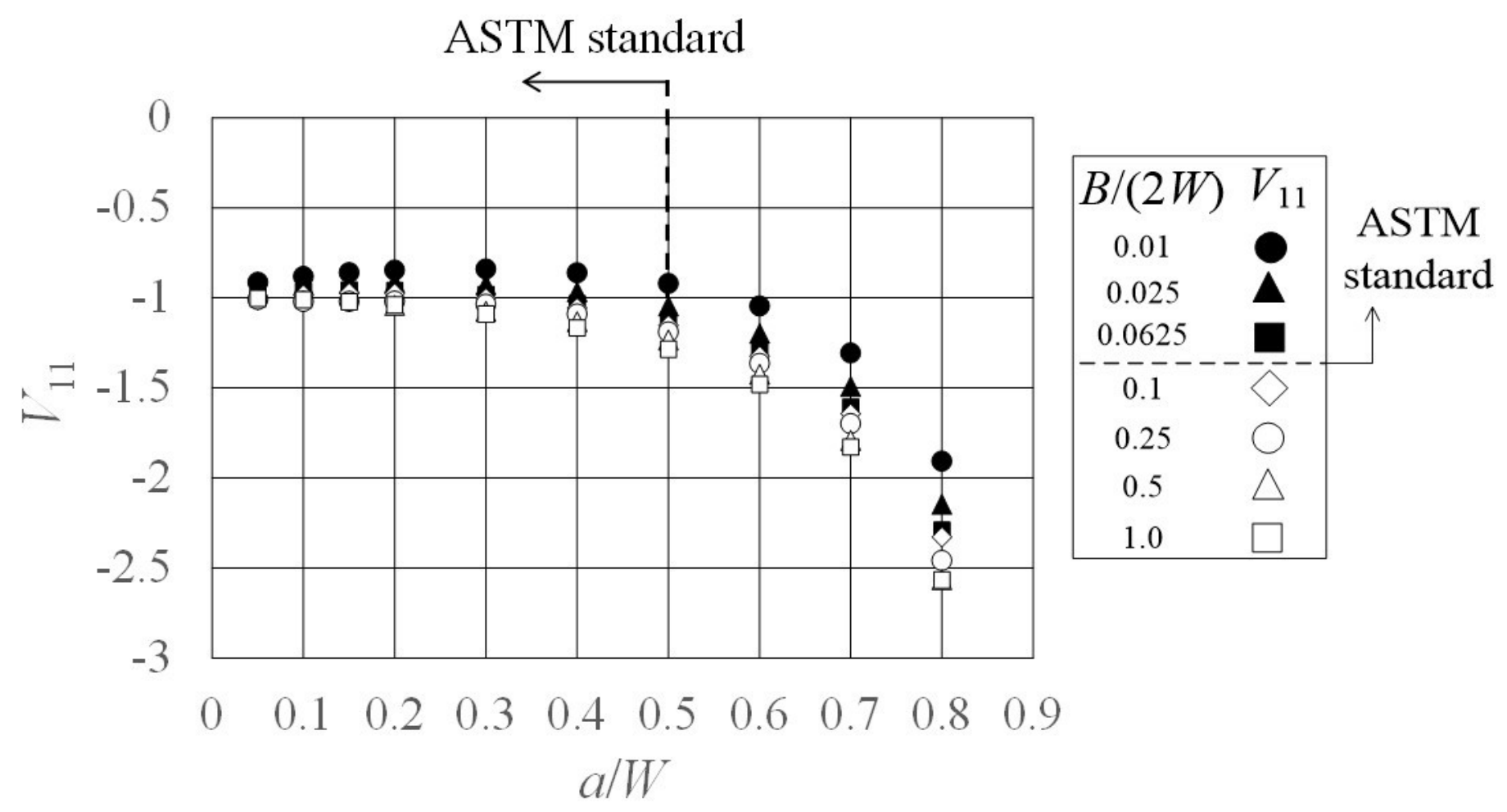

Fig. 5 Normalized $T_{11}$ solutions $\left(V_{11}=T_{11} / \sigma_{0}\right)$ at the specimen mid-plane for CCT specimens $(v=0.3)$ 


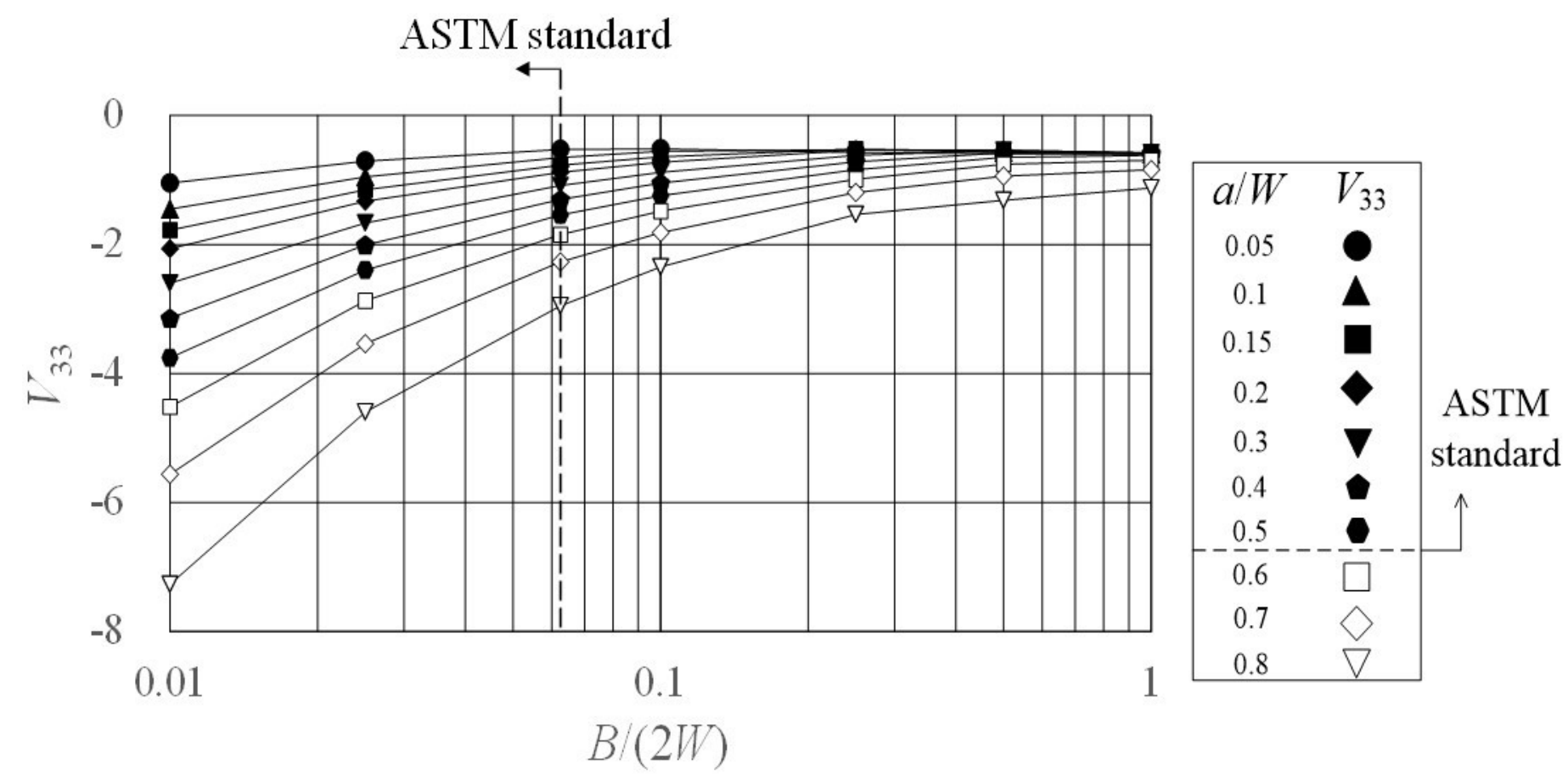

Fig. 6 Normalized $T_{33}$ solutions $\left(V_{33}=T_{33} / \sigma_{0}\right)$ at the specimen mid-plane for CCT specimens $(v=0.3)$ 


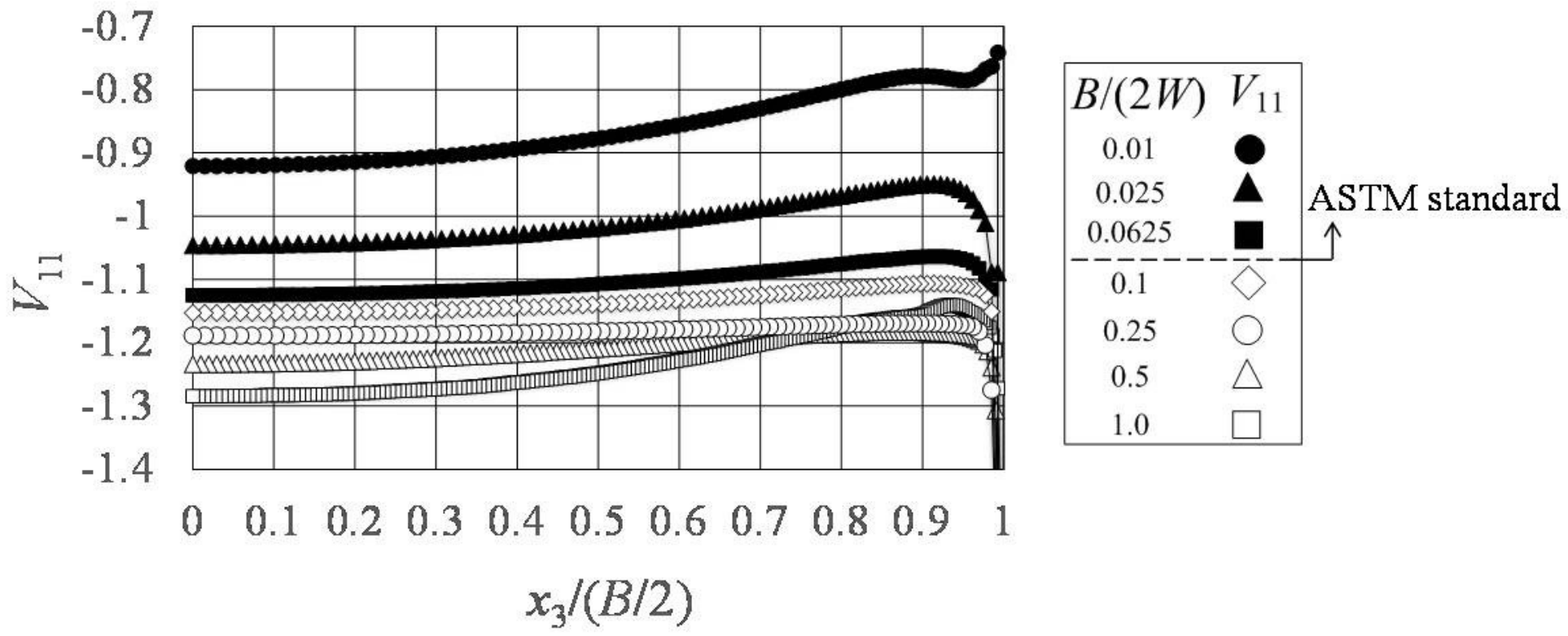

Fig. 7 Normalized $T_{11}$ solutions $\left(V_{11}=T_{11} / \sigma_{0}\right)$ vs. $x_{3} /(B / 2)$ for the CCT specimens with various thicknesses $(a / W=0.5 ; v=0.3)$ 


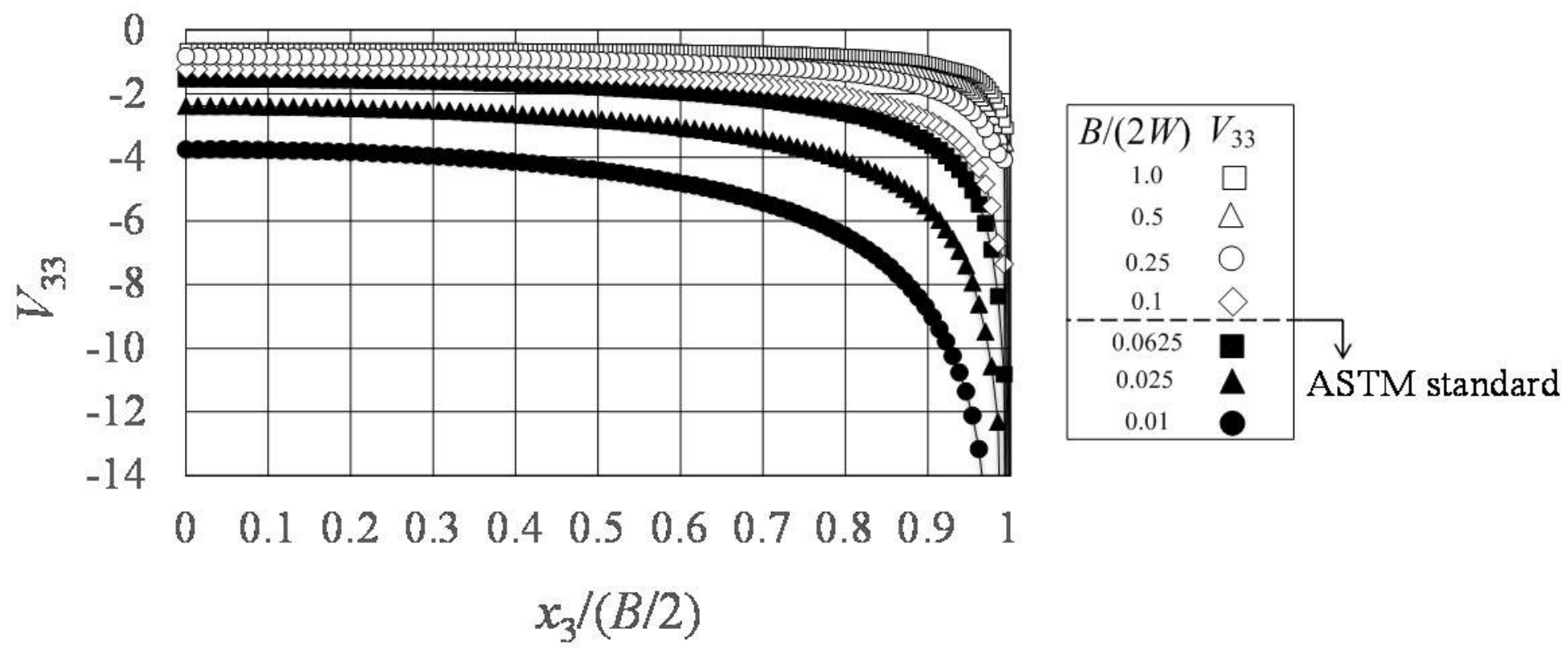

Fig. 8 Normalized $T_{33}$ solutions $\left(V_{33}=T_{33} / \sigma_{0}\right)$ vs. $x_{3} /(B / 2)$ for the CCT specimens with various thicknesses $(a / W=0.5 ; v=0.3)$ 


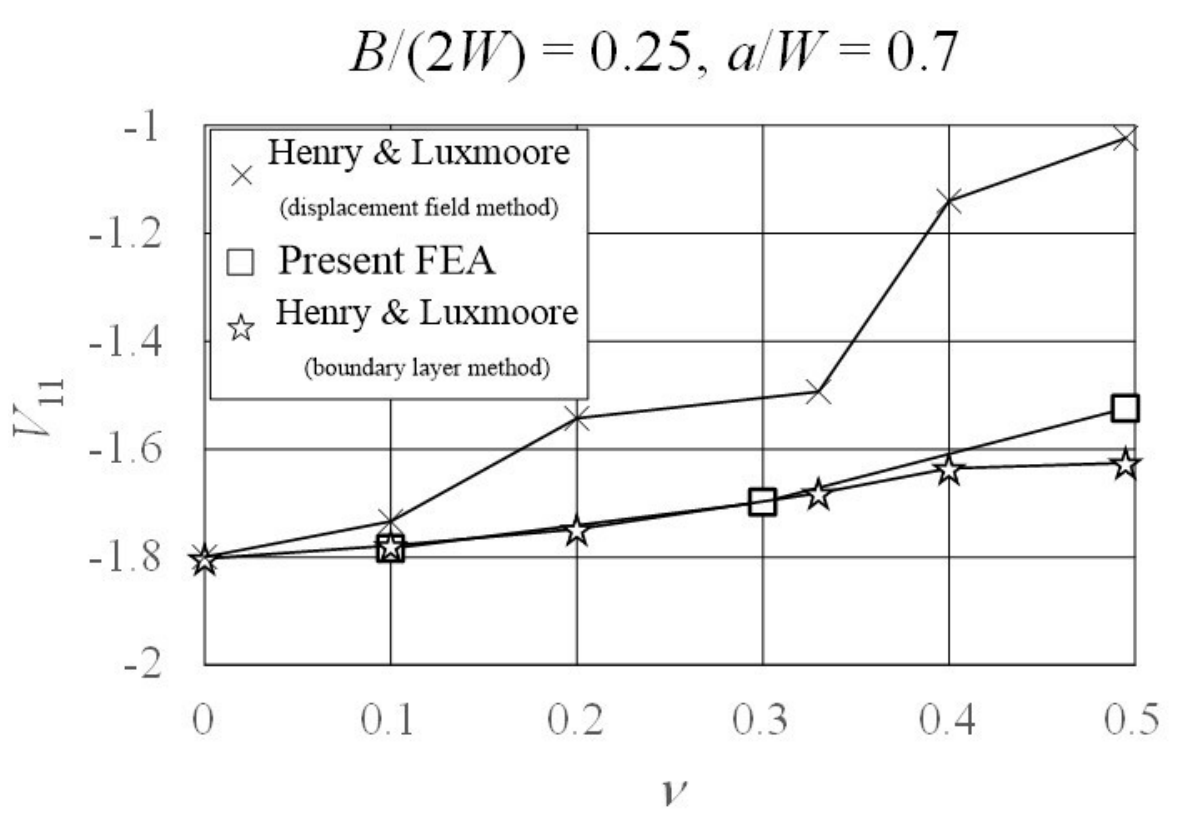

(a)

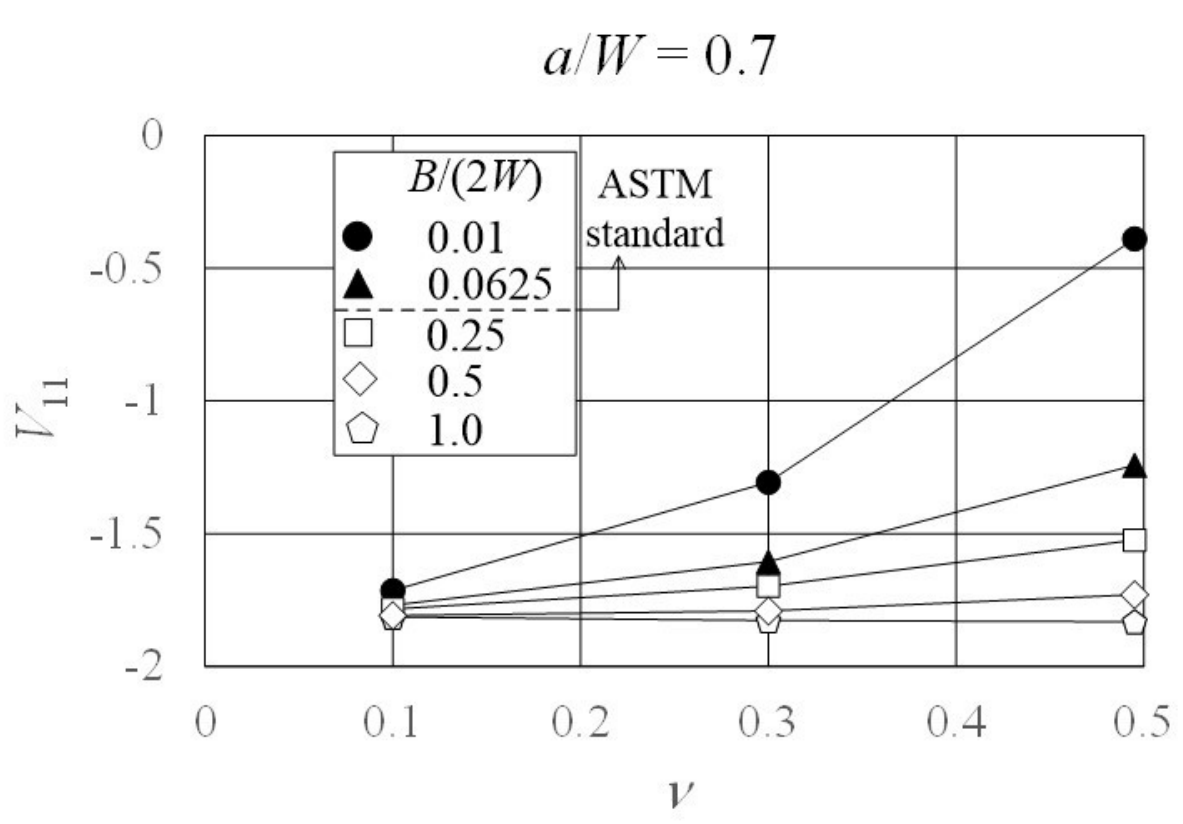

(b)

Fig. 9 Effects of Poisson's ratio $v$ on the mid-plane $V_{11}$ for the case of $a / W=0.7$ : (a) comparison of present $V_{11}$ for $B /(2 W)=0.25$ with Henry and Luxmoore's results [24] (b) present $V_{11}$ for various thicknesses 


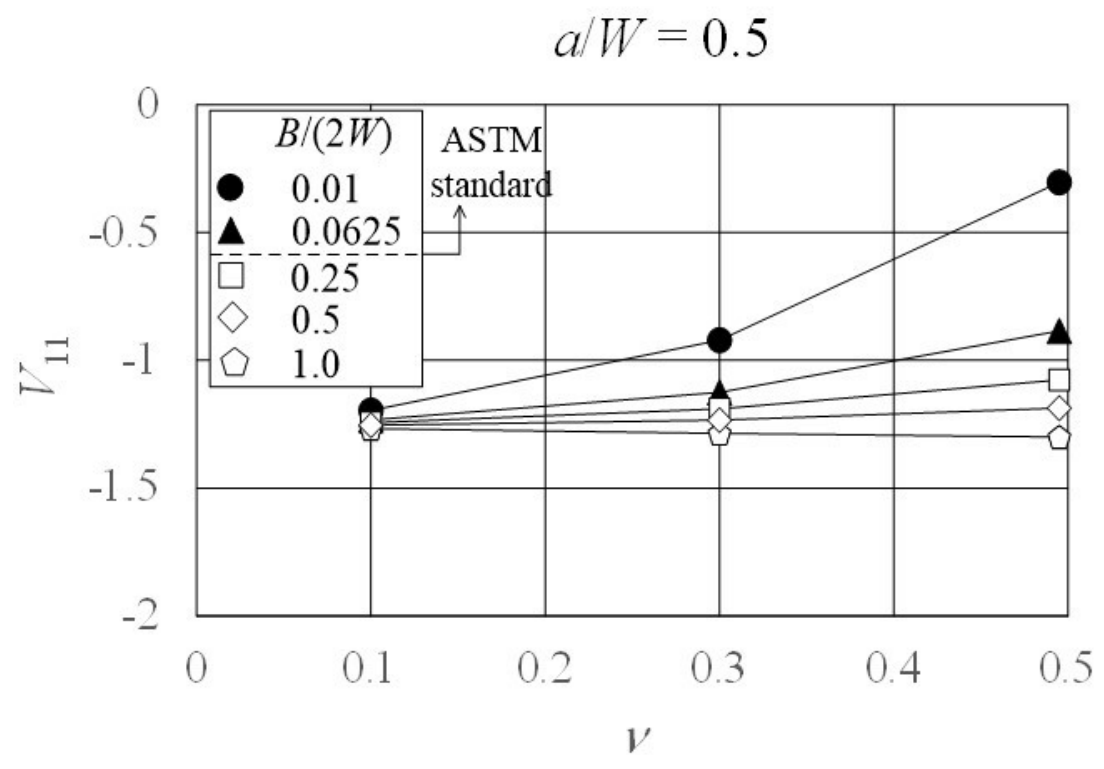

(a) The mid-plane $V_{11}$ vs. Poisson's ratio $v$

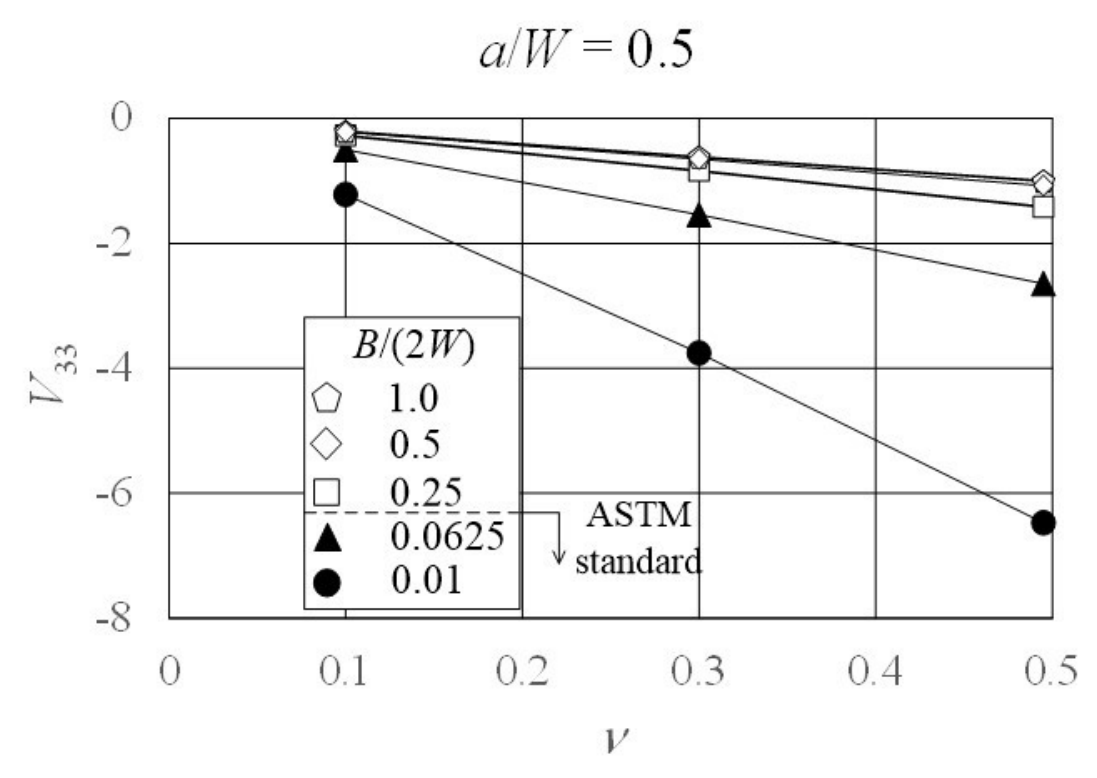

(b) The mid-plane $V_{33}$ vs. Poisson's ratio $v$

Fig. 10 Effects of Poisson's ratio $v$ on the mid-plane $V_{11}$ and $V_{33}$ for a case of $a / W=0.5$ : (a) $V_{11}$ vs. $v$, (b) $V_{33}$ vs. $v$ 


\section{Highlights}

1. T-stresses for CCT specimens with various crack lengths and thicknesses were obtained.

2. $T_{11}$ and $T_{33}$ were negative for all of the CCT specimens studied in this work.

3. Both $T_{11}$ and $T_{33}$ changed significantly for the ASTM E2472 standard CCT specimens. 